BMC

Evolutionary Biology

Photo by Manuel Hiß

Molecular evidence for convergent evolution and allopolyploid speciation within the PhyscomitriumPhyscomitrella species complex

Beike et al. 


\title{
Molecular evidence for convergent evolution and allopolyploid speciation within the Physcomitrium- Physcomitrella species complex
}

Anna K Beike ${ }^{1,2}$, Mark von Stackelberg ${ }^{2,4}$, Mareike Schallenberg-Rüdinger ${ }^{10}$, Sebastian T Hanke ${ }^{1,3,10}$, Marie Follo ${ }^{6}$, Dietmar Quandt ${ }^{5}$, Stuart F McDaniel ${ }^{7}$, Ralf Reski ${ }^{2,3,8,9}$, Benito C Tan ${ }^{11}$ and Stefan A Rensing ${ }^{1,3,9,10^{*}}$

\begin{abstract}
Background: The moss Physcomitrella patens (Hedw.) Bruch \& Schimp. is an important experimental model system for evolutionary-developmental studies. In order to shed light on the evolutionary history of Physcomitrella and related species within the Funariaceae, we analyzed the natural genetic diversity of the Physcomitrium-Physcomitrella species complex.

Results: Molecular analysis of the nuclear single copy gene BRK1 reveals that three Physcomitrium species feature larger genome sizes than Physcomitrella patens and encode two expressed BRK1 homeologs (polyploidization-derived paralogs), indicating that they may be allopolyploid hybrids. Phylogenetic analyses of BRK1 as well as microsatellite simple sequence repeat (SSR) data confirm a polyphyletic origin for three Physcomitrella lineages. Differences in the conservation of mitochondrial editing sites further support hybridization and cryptic speciation within the Physcomitrium-Physcomitrella species complex.

Conclusions: We propose a revised classification of the previously described four subspecies of Physcomitrella patens into three distinct species, namely Physcomitrella patens, Physcomitrella readeri and Physcomitrella magdalenae. We argue that secondary reduction of sporophyte complexity in these species is due to the establishment of an ecological niche, namely spores resting in mud and possible spore dispersal by migratory birds. Besides the Physcomitrium-Physcomitrella species complex, the Funariaceae are host to their type species, Funaria hygrometrica, featuring a sporophyte morphology which is more complex. Their considerable developmental variation among closely related lineages and remarkable trait evolution render the Funariaceae an interesting group for evolutionary and genetic research.
\end{abstract}

Keywords: Physcomitrella patens, Funariaceae, Hybridization, Polyploidization, Speciation

\section{Background}

A major goal in evolutionary biology is to understand the processes that generate new species. Until recently, genetic analyses of species differences have relied on a small number of model systems. Here we examine patterns of divergence among relatives of the moss Physcomitrella patens (Hedw.) Bruch \& Schimp., the first bryophyte with completely sequenced and well-annotated nuclear,

\footnotetext{
* Correspondence: stefan.rensing@biologie.uni-marburg.de

${ }^{10}$ Plant Cell Biology, Faculty of Biology, University of Marburg,

Karl-von-Frisch-Str. 8, 35043 Marburg, Germany

Full list of author information is available at the end of the article
}

plastid and mitochondrial genomes [1-4]. P. patens belongs to the Funariaceae, a family of small, terricolous mosses with highly diverse sporophyte morphology. In contrast to other Funariaceae, Physcomitrella is characterized by a short sporophyte lacking many of the ornamentations typical in mosses. The history of the genus was reviewed by Tan [5]. The Index Muscorum [6] listed four species in the genus Physcomitrella. Of the four taxa, Physcomitrella austro-patens Broth. and $P$. californica H.A. Crum and L.E. Anderson were treated later as synonyms of $P$. readeri (Müll. Hall.) I.G. Stone \& G.A.M. Scott. Physcomitrella hampei Limpr. was interpreted as a hybrid species [5-7]. However, based on

\section{Biomed Central}

(c) 2014 Beike et al.; licensee BioMed Central Ltd. This is an Open Access article distributed under the terms of the Creative Commons Attribution License (http://creativecommons.org/licenses/by/2.0), which permits unrestricted use, distribution, and reproduction in any medium, provided the original work is properly credited. The Creative Commons Public Domain Dedication waiver (http://creativecommons.org/publicdomain/zero/1.0/) applies to the data made available in this article, unless otherwise stated. 
variable but overlapping phenotypic characteristics, a revised classification of the genus Physcomitrella was subsequently proposed by Tan [5], which described Physcomitrella as one single polymorphic species with four subspecies, namely $P$. patens ssp. patens from Europe, P. patens ssp. readeri (Müll. Hal.) B.C. Tan from Australia, P. patens ssp. californica (H.A. Crum \& L.E. Anderson) B.C. Tan from California (North America) and Japan, and $P$. patens ssp. magdalenae (de Sloover) B.C. Tan from Rwanda (Africa). Currently, the majority of bryologists accept three separate species, namely Physcomitrella patens, $P$. readeri and $P$. magdalenae De Sloover. $P$. patens has a wide distribution in the Northern Hemisphere, $P$. readeri is found in California (North America), Australia and Japan [8], while P. magdalenae has been reported from Rwanda, Africa $[9,10]$. Recent data suggest that the Physcomitrella phenotype arose three times within the Physcomitrium-Physcomitrella species complex, based on phylogenetic analyses of nuclear, chloroplast, and mitochondrial DNA sequence data $[11,12]$. Here, the species complex is defined as a taxonomic group of intergraded phenotypes that hinders separation based on morphological traits. Due to the fact that Physcomitrella has been classified as a single species based on similar morphological characters of the sporophytes, it has been argued that such characters should not be used for classification [11]. In order to test the polyphyletic origin of the genus Physcomitrella and to analyze whether monophyletic groups corresponding to species can be resolved within Physcomitrella, we performed phylogenetic analyses of a nuclear single copy gene (BRK1) [13] and microsatellite simple sequence repeat (SSR) data amplified from numerous accessions covering all four Physcomitrella subspecies and further Funariaceae.

Regarding the sequenced $P$. patens strain from Gransden (Europe), the haploid chromosome number of $n=27$ for meiotic and mitotic cells $[14,15]$ provides evidence for a complex history of polyploidization, since the base number of chromosomes is reported to be $n=4-7$ among mosses [16-18]. Genome duplication or polyploidization is an important mechanism of eukaryotic evolution [19-22] and considered to be of particular relevance in the speciation and diversification of land plants. Molecular data have confirmed that $P$. patens is a paleopolyploid that underwent at least one whole-genome duplication event approximately 45 MYA during the Eocene [23]. However, some other Funariaceae from within the Physcomitrium-Physcomitrella species complex have even higher chromosome numbers ranging, e.g., from $n=9$ to $n=72$ for Physcomitrium pyriforme, or $\mathrm{n}=9$ to $\mathrm{n}=54$ for Physcomitrium eurystomum [18]. Taking this into account, along with the fact that some Funariaceae show interfertility $[5,12,24,25]$, a considerable number of polyploids, including allopolyploid hybrid species, can be expected. Natural hybrids among the Funariaceae, typically characterized by intermediate sporophytic characteristics [26,27], have also been described from the field [28-31]. The putative hybrid origin of Physcomitrium collenchymatum and P. eurystomum was recently been suggested based on molecular data and genealogical analyses of six different loci, including ribosomal, plastidic, and nuclear marker genes [12]. However, scarce evidence for polyploidizationderived paralogs (homeologs) of single copy genes in the analyzed Physcomitrium species has been shown to date.

In this study, we analyzed genome sizes and homeologs of the nuclear single copy gene $B R K 1$ [13] across a broad range of Funariaceae accessions in order to test whether species belonging to the genus Physcomitrium are allopolyploid hybrids. We chose $B R K 1$ as a phylogenetic marker gene as it is a single copy gene in nearly all of the land plant genomes sequenced to date (Additional file 1: Figure S2). In addition, we assessed the requirement of RNA editing sites to be edited, since out of $13 \mathrm{P}$. patens editing sites (cytidines which are post-transcriptionally changed into uridines) $[32,33]$ three are not present in Funaria hygrometrica [34], thus rendering the pattern of editing site gain and loss a potentially informative evolutionary feature within the Funariaceae. Based on phylogenetic analysis of the novel marker gene BRK1, microsatellite-derived genetic distances and different editing patterns, we have revised the Physcomitrella subspecies sensu Tan [5] and hypothesize on speciation and the mode of spore dispersal in Physcomitrella.

\section{Methods}

\section{Funariaceae in vitro collection, culture and observation}

Numerous Funariaceae accessions (determined by the collectors) were contributed to the authors (Table 1) and established in axenic in vitro culture as previously described [12,35]. All plants originated from recent isolates except the $P$. patens accession from Gransden (Europe) which derives from a single spore isolated by H.L.K. Whitehouse in 1962 [14]. Information about locality, habitat, collectors, year of collection, International Moss Stock Center (IMSC) numbers and vouchers, as well as molecular, morphological and flow cytometric data are available for selected species from that collection (Additional file 2: Table S1). Plants from two capsules collected at the same location were denoted with a "K" and the capsule number. At present, the in vitro collection comprises 38 Funariaceae accessions from different worldwide locations (Additional file 2: Table S1). These accessions were assigned to taxa according to the species classification of the collectors and encompass 20 Physcomitrella, 14. Physcomitrium, three Funaria and one Aphanorrhegma accession. The Physcomitrella accessions comprise plants from regions where the four different subspecies were originally found $[5,10]$. P . patens ssp. 
Table 1 Funariaceae species collection

\begin{tabular}{|c|c|c|c|c|}
\hline Species (revised) & Locality & Region & Collector & $\begin{array}{l}\text { Physcomitrella } \\
\text { subspecies } \\
\text { (sensu Tan) }\end{array}$ \\
\hline \multirow[t]{15}{*}{ Physcomitrella patens } & Gransden Wood, Huntigdonshire, UK & Europe & Whitehouse & patens \\
\hline & Nene Washes, Cambridge, UK & Europe & Preston & patens \\
\hline & Cholsey, Berkshire, UK & Europe & Porley & patens \\
\hline & Bad Honnef, Grafenwerth, Rheinland-Pfalz, Germany & Europe & Frahm & patens \\
\hline & Heimerbrühl, Rheinland-Pfalz, Germany & Europe & Wolff & patens \\
\hline & Nennig, Saarland, Germany & Europe & Caspari & patens \\
\hline & Martinshof, Saarland, Germany & Europe & Caspari & patens \\
\hline & Villersexel, Haute Saône, France (K3 + K4) & Europe & Lüth & patens \\
\hline & Lviv, Ukraine & Europe & Lobachevska & patens \\
\hline & Wik castle, Uppsala, Sweden & Europe & $\begin{array}{l}\text { Nilsson, Thelander, Olsson, } \\
\text { Ronne }\end{array}$ & patens \\
\hline & Trondheim, Norway & Europe & Hassel & patens \\
\hline & Gemünd, Nordrhein-Westfalen, Germany (K5) & Europe & Frahm & patens \\
\hline & $\begin{array}{l}\text { Gemünd, Nordrhein-Westfalen, Germany (K1) } \\
\text { (var. megapolitana) }\end{array}$ & Europe & Frahm & patens \\
\hline & Kaskaskia Island, Illinois, USA & $\begin{array}{l}\text { North } \\
\text { America }\end{array}$ & Sargent \& Vitt & patens \\
\hline & Del Valle Lake, California, USA & $\begin{array}{l}\text { North } \\
\text { America }\end{array}$ & Mishler & californica \\
\hline \multirow[t]{4}{*}{ Physcomitrella readeri } & Kumamoto, Shisui-cho, Kyushu, Japan & Japan & Ono \& Deguchi & californica \\
\hline & Saitama, Iwatsuki-shi, Honshu, Japan & Japan & Higuchi & californica \\
\hline & Okayama, Honshu, Japan & Japan & Hasebe & californica \\
\hline & Melton Reservoir, Victoria, Australia & Australia & Stajsic \& Klazenga & readeri \\
\hline $\begin{array}{l}\text { Physcomitrella } \\
\text { magdalenae }\end{array}$ & Mt. Bisoke, Ruhengeri, Rwanda & Africa & Solga \& Buchbender & magdalenae \\
\hline \multirow{3}{*}{$\begin{array}{l}\text { Physcomitrium } \\
\text { sphaericum }\end{array}$} & Grosshartmannsdorf, Osterzgebirge, Sachsen, Germany & Europe & Frahm & \\
\hline & Imsbach-Aue, Saarland, Germany & Europe & Wolff & \\
\hline & Vellescot, Territore-de-Belfort, France & Europe & Lüth & \\
\hline \multirow[t]{3}{*}{$\begin{array}{l}\text { Physcomitrium } \\
\text { eurystomum }\end{array}$} & $\begin{array}{l}\text { Neukirch, Allgäu West, Wangen, Bodenseekreis, Baden- } \\
\text { Württemberg, Germany }\end{array}$ & Europe & Schäfer-Verwimp & \\
\hline & Neustadt, Thüringen, Germany & Europe & Eckstein & \\
\hline & Schleiz, Thüringen, Germany & Europe & Eckstein & \\
\hline \multirow[t]{7}{*}{ Physcomitrium pyriforme } & Bischofswerda, Sachsen, Germany & Europe & Eckstein & \\
\hline & Nordhausen, Liebenrode, Thüringen, Germany & Europe & Eckstein & \\
\hline & Waltershof, Gera, Thüringen, Germany & Europe & Eckstein & \\
\hline & Haardtrand, Ebekoben, Rheinland-Pfalz, Germany & Europe & Lauer & \\
\hline & Övergran, Biskops-Arnö, Uppland, Sweden & Europe & Lönnell & \\
\hline & Madeira, Portugal & Europe & Eckstein & \\
\hline & Durham, Orange County, North Carolina, USA & $\begin{array}{l}\text { North } \\
\text { America }\end{array}$ & Goffinet & \\
\hline $\begin{array}{l}\text { Physcomitrium } \\
\text { collenchymatum }\end{array}$ & Shaw Nature Reserve, Franklin County, MO, USA (K1, K2A, K2B) & $\begin{array}{l}\text { North } \\
\text { America }\end{array}$ & Allen \& Darigo & \\
\hline Funaria hygrometrica & Durham, Orange County, North Carolina, USA & $\begin{array}{l}\text { North } \\
\text { America }\end{array}$ & Goffinet & \\
\hline
\end{tabular}


Table 1 Funariaceae species collection (Continued)

\begin{tabular}{lll}
\hline Funaria americana & Canada, Alberta & North \\
Funaria flavicans & Durham, Orange County, North Carolina, USA & North \\
& & America Goffinet \\
Aphanorrhegma serratum & Arkansas, USA & North \\
& & America Buck
\end{tabular}

Several Funariaceae were contributed to the authors and established in axenic in vitro culture. The name of each species, locality, region and collector are listed for each accession. For Physcomitrella, the revised taxon name according to the new classification proposed here is listed on the left, while the former name of the subspecies as described by the collector is listed on the right. For further information, e.g. year of collection, habitat and available data (BRK1, SSRs, editing analysis, genome size, IMSC number) see Additional file 2: Table S1.

patens is represented by 14 accessions from different regions of Europe and one accession from North America. $P$. patens ssp. californica accessions are available from North America and Japan, one from the southern island Kyushu and two from the central island Honshu. P. patens ssp. magdalenae was collected in Rwanda, Africa. One accession of $P$. patens ssp. readeri is available from the Melton Reservoir in Australia. In addition to that, Aphanorrhegma serratum and three Funaria species from North America are represented in the collection. Concerning Physcomitrium, three P. sphaericum accessions, three $P$. eurystomum accessions, seven $P$. pyriforme accessions from Europe and North America and one $P$. collenchymatum accession from North America are also available (Table 1, Additional file 2: Table S1).

Plants were cultivated on solid mineral Knop medium [36] as previously described [37]. For standardized observation of gametophytic features, plants were grown on Petri dishes (9 $\mathrm{cm}$ diameter) wrapped with laboratory film. Environmental conditions were set to 22 degrees Celsius and a long day ( $16 \mathrm{~h}$ light, $8 \mathrm{~h}$ dark) light cycle (white light at $70 \mu \mathrm{mol} * \mathrm{~s}^{-1} * \mathrm{~m}^{-2}$ ). Plants were established by transfer of individual gametophores, and observed under a stereo binocular (Zeiss, Germany) after several weeks to months of growth.

\section{Genomic DNA extraction}

Genomic DNA was extracted from moss tissue following the cetyltrimethyl ammonium bromide (CTAB) method described by [38]. Up to $100 \mathrm{mg}$ of moss material was disrupted with a Tissue Lyser (Qiagen, Hilden, Germany) and incubated for $30 \mathrm{~min}$ in $700 \mu \mathrm{L}$ CTAB buffer $(2 \%$ CTAB, 1.4 M NaCl, $20 \mathrm{mM}$ EDTA, $0.5 \%$ PVP 40, $100 \mathrm{mM}$ Tris/HCl, pH 8.0; $0.2 \%$ 2-mercaptoethanol [v/v] added before use). Subsequently, $600 \mu \mathrm{L}$ chloroform: isoamylalcohol (24:1) was added. Phase separation was reached after vigorous mixing by centrifugation $(16,100 \times \mathrm{g})$ for $5 \mathrm{~min}$. The aqueous phase was transferred to a fresh tube and $2 / 3$ [v:v] isopropanol was added for precipitation at $-20{ }^{\circ} \mathrm{C}$ overnight. The DNA was sedimented by centrifugation $(20,817 \mathrm{x} \mathrm{g})$ for $30-45 \mathrm{~min}$ at $4{ }^{\circ} \mathrm{C}$. The supernatant was removed and the pellet was washed twice with $200 \mu \mathrm{L}$ of $70 \%$ ethanol. After centrifugation $(16,100 \times \mathrm{g})$, the supernatant was removed. DNA was dissolved in $100 \mu \mathrm{L}$ TE buffer (0.1 M TrisHCl, 0.01 M EDTA, pH 7.5 with $\mathrm{HCl})$. For RNAse digestion, $10 \mu \mathrm{g}$ RNAse A $(10 \mathrm{mg} / \mathrm{mL}$, Thermo Scientific, St. Leon-Rot, Germany) were added and the DNA was incubated for $1 \mathrm{~h}$ at $37{ }^{\circ} \mathrm{C}$. RNAse digestion was controlled and DNA concentration was determined by gel electrophoresis in $1 \%$ agarose gels.

\section{Amplification of BRK1 from genomic DNA}

A part of the nuclear gene BRK1 (Pp1s35_157V6.1) was amplified using the primers BRICK1_for: GTCGGCATTG CTGTACAA and BRICK1_rev: CTCCAGCTGACGCT CCAG. The PCR was performed in $20 \mu \mathrm{L}$ reaction volume containing $2 \mu \mathrm{L} 10 \times$ Buffer E (Genaxxon, Biberach, Germany), $0.4 \mu \mathrm{L}$ deoxyribonucleotide triphosphates (dNTPs, 10 mM, Thermo Scientific, St. Leon-Rot, Germany), 1.25 U Taq polymerase (Genaxxon, Biberach), $0.5 \mu \mathrm{l}$ of each primer $(10 \mathrm{pmol} / \mu \mathrm{L})$ and $1 \mu \mathrm{L}$ genomic DNA (50$100 \mathrm{ng} / \mu \mathrm{L})$. The PCR cycling conditions consisted of an initial denaturation at $94{ }^{\circ} \mathrm{C}$ for $5 \mathrm{~min}$, followed by cycling conditions which consisted of a denaturation step of $45 \mathrm{~s}$ at $94{ }^{\circ} \mathrm{C}$, annealing at $52{ }^{\circ} \mathrm{C}$ for $1 \mathrm{~min}$ and elongation at $72{ }^{\circ} \mathrm{C}$ for $1 \mathrm{~min}$ for a total of 30 cycles. The PCR products were eluted and purified from a $1 \%$ agarose gel with the QIAquick Gel Extraction Kit (Qiagen, Hilden, Germany) according to the manufacturer's instructions.

\section{Cloning of BRK1 and plasmid DNA extraction}

The PCR sequencing products of P. eurystomum, P. collenchymatum and P. pyriforme showed overlapping sequence peaks (polymorphisms) in the electropherogram (Figure 1A). In order to obtain clear sequences for potentially multiple loci of BRK1 for these species, the PCR products were cloned into the blunt end vector pJET1.2/blunt according to the manufacturer's protocol (CloneJET $^{\mathrm{m} \mathrm{m}}$ Molecular Cloning Kit, Thermo Scientific, St. Leon-Rot, Germany). The vector was transformed into $E$. coli cells, which were incubated overnight on solid ampicillin-containing LB medium at $37{ }^{\circ} \mathrm{C}$ for selection. Bacterial colonies were screened for the insertion of plasmid DNA via PCR using the pJET1.2/blunt primers pJet_T7_for: TAATACGACTCACTATAGGG and pJet_rev: GAAGAACATCGATTTTCCATGGCAGC. 


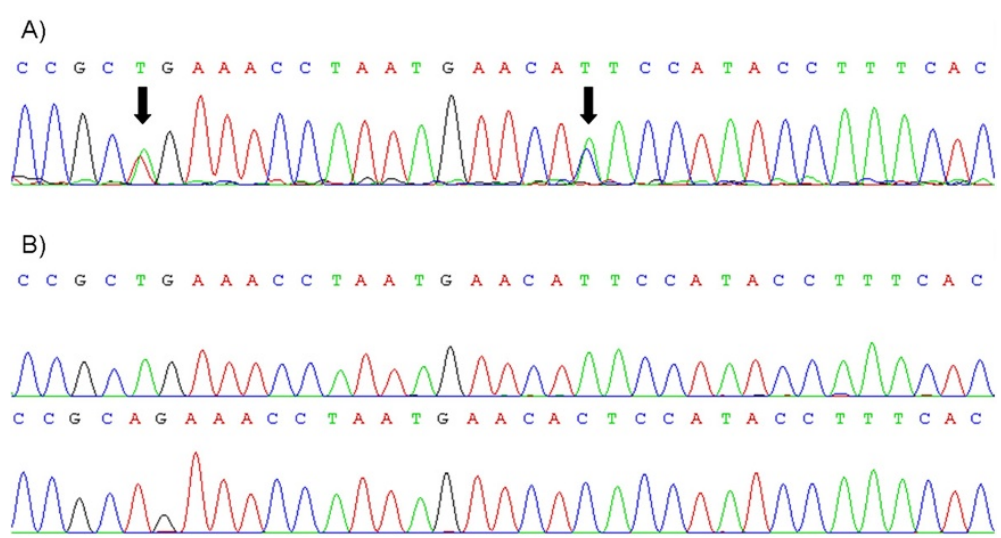

Figure 1 Electropherograms of the BRK1 intron region from Physcomitrium eurystomum. (A) Direct sequencing product of BRK1 amplified from P. eurystomum (Schleiz, Europe) genomic DNA. Sequence polymorphisms are indicated with black arrows. (B) Clonal sequencing products of the BRK1 showing two distinct homeologs of BRK1 in P. eurystomum. Figure generated using Gentle (http://gentle.magnusmanske.de/).

Plasmid DNA extraction was performed after an overnight incubation in ampicillin-containing liquid LB medium at $37{ }^{\circ} \mathrm{C}$ using the GeneJET ${ }^{\mathrm{TM}}$ Plasmid Miniprep-Kit (Thermo Scientific, St. Leon-Rot, Germany).

\section{Direct sequencing of $B R K 1$ PCR products and of plasmid clones}

In total, $10-50 \mathrm{ng} / \mu \mathrm{L}$ of the purified PCR product were sent for sequencing to GATC Biotech AG (Konstanz, Germany) using the primers BRICK1_for and BRICK1_rev. Plasmid DNA was sent in concentrations of 30-100 ng/ $\mu \mathrm{L}$ and Sanger sequenced (GATC Biotech AG, Konstanz, Germany) with a standard sequencing primer for the blunt end vector pJET1.2/blunt (Thermo Scientific, St. LeonRot, Germany). For accessions with polymorphic direct PCR sequencing products, up to 10 plasmid DNAs from independent clones were sent for sequencing, respectively. Sequences which were obtained at least twice independently were considered true and used for phylogenetic analyses. Exceptions to this were both sequences of BRK1 for one $P$. pyriforme accession (Nordhausen, Europe), and one sequence representing one locus of $P$. collenchymatum (Shaw Nature Reserve, Franklin County, MO, USA) which were each obtained only once. These sequences were included into further analyses since they were found to be identical to corresponding sequences of other accessions from the same species.

\section{BRK1 sequence analysis}

The sequence chromatograms were analyzed with the ChromasPro software, version 1.34 (http://www. technelysium.com.au/ChromasPro.html). Multiple sequence alignments were calculated with MUSCLE 3.51 [39] and visualized with Jalview [40]. The gene structure of BRK1 was annotated within the multiple sequence alignment according to the gene structure found in $P$. patens (Pp1s35_157V6.1, Additional file 3: Figure S1). Neighbor-joining analysis was performed with QUICKTREE_SD [41,42] using 1,000 bootstrap replicates. Bayesian inference was carried out with MrBayes [43], using the GTR model with eight gamma distributed rates, invariant sites, two hot and two cold chains, burn-in 250 and two million generations, until the standard deviation of split frequencies dropped below 0.01. Maximum likelihood inference was carried out with TREE-PUZZLE [44] using the GTR model with eight gamma-distributed rates, quartet puzzling (10,000 steps) and exact parameter estimation. While the Maximum Likelihood tree is shown, support values from all three methods are plotted on the tree (see legend). The tree was visualized with FigTree v1.1.2 (http://tree.bio.ed.ac.uk/software/figtree/).

\section{RNA editing analysis}

DNA was prepared from plant material using the extraction method described by [45]. Primer pairs bordering regions of nad3, nad4, nad5 (subunits of complex I, amplicon length 343 bp, 392 bp and 459 bp, respectively), cox1 (subunit of complex IV, 252 bp), rps14 (ribosomal protein S14, $246 \mathrm{bp}$ ) and ccmFC (cytochrome biogenesis factor subunit $\mathrm{C}, 210 \mathrm{bp}$ ) harboring mitochondrial editing sites identified in the $P$. patens accession from Gransden [34], were used for PCR assays. Amplification assays were performed as described [34]. PCR products were gel-purified using the HiYield PCR Clean-up \& Gel-Extraction kit (Südlaborbedarf $\mathrm{GmbH}$, Gauting, Germany) or purified using ExoSAP-IT (Affymetrix, Santa Clara, USA) and Sanger sequenced (GATC Biotech AG, Konstanz, Germany). DNA sequences were aligned to the corresponding coding sequences of $P$. patens and Funaria hygrometrica [34] using Mega 5.0 [46] and putative editing sites were identified via PREPACT 2.0 [47]. 


\section{Amplification of EST-derived microsatellites}

Genomic DNA was extracted as previously described [48]. Sixty-four simple sequence repeat (SSR) loci with available polymorphism information content (Table http://www. cosmoss.org/376_PCR_tested_SSRs.xls on http://www. cosmoss.org/genmap.content) were chosen from a collection of EST-derived microsatellites [48]. In total, 49 loci were found to be suitable by means of PCR, using the respective first primer pair listed; the SSR numbering in Additional file 4: Table S2 corresponds to the one in the above mentioned original data. SSR loci were amplified in a $20 \mu \mathrm{L}$ PCR mix containing $2 \mu \mathrm{l}$ of $10 \times$ RED-Taq-PCR buffer, $0.1 \mathrm{mM}$ dATP, dCTP, dGTP and dTTP, 5 pmol each of two primers, 0.5 U RED-Taq-Polymerase (SigmaAldrich, Deisenhofen, Germany) and 4 ng genomic DNA. PCR was carried out starting with an initial DNA denaturation at $95{ }^{\circ} \mathrm{C}$ for $2 \mathrm{~min}$. The first cycle consisted of $30 \mathrm{~s}$ denaturation at $92{ }^{\circ} \mathrm{C}$, with primer annealing for $30 \mathrm{~s}$ at $60{ }^{\circ} \mathrm{C}$ and elongation for $30 \mathrm{~s}$ at $72{ }^{\circ} \mathrm{C}$. In each of the 10 subsequent cycles, the annealing temperature was decreased by $0.7^{\circ} \mathrm{C}$. The final 25 cycles consisted of $15 \mathrm{~s}$ denaturation at $92{ }^{\circ} \mathrm{C}, 15 \mathrm{~s}$ primer annealing at $52{ }^{\circ} \mathrm{C}$ and $30 \mathrm{~s}$ elongation at $72{ }^{\circ} \mathrm{C}$. SSR PCR products were size separated in $3 \%$ MetaPhor (Cambrex Corporation, East Rutherford, USA) high resolution agarose by gel electrophoresis in 0.5 fold TBE ( $45 \mathrm{mM}$ Tris-borate, $1 \mathrm{mM}$ EDTA, $\mathrm{pH}$ 8.0) and visualized by ethidium bromide staining.

\section{SSR data analysis}

SSR loci were scored manually for all included accessions according to their amplified fragment size. Distinguishable sizes were scored as different alleles; indistinguishable sizes were scored as the same allele (Additional file 4: Table S2). Absence of PCR products was scored as a haploid null allele. The data set included all Physcomitrella accessions as well as Physcomitrium sphaericum (Additional file 2: Table S1). Genetic distances were calculated with Nei's DA distance algorithm [49]. The phylogenetic tree was constructed with the Neighbor-Joining algorithm [50] using 1,000 bootstrap replicates. For genetic distance and phylogenetic tree calculations the software POPULATION 1.2.28 [51] was used and the tree was visualized using FigTree (http://tree.bio.ed.ac.uk/software/figtree/). In addition, the different sized alleles derived from the 49 SSR loci were transformed into 170 binary presence/ absence characters (null alleles were scored as gaps). The binary encoding might overestimate variation, but was necessary since SplitsTree does not allow presentation of the data in a continuous fashion. Based on this matrix (Additional file 4: Table S2), SplitsTree 4 [52] was used to calculate GeneContent distances and a bootstrapped (1,000 replicates) NeighborNet.

\section{Flow cytometry}

Gametophores, pre-cultured for four weeks, were chopped using a razor blade in buffer $\left(0.107 \mathrm{~g} \mathrm{MgCl}_{2}{ }^{*} 6 \mathrm{H}_{2} \mathrm{O}, 0.5 \mathrm{~g}\right.$ $\mathrm{NaCl}, 1.211 \mathrm{~g}$ Tris, $0.1 \mathrm{~mL}$ Triton X-100 in $100 \mathrm{~mL}$ water, $\mathrm{pH} 7.0$ with $\mathrm{HCl}$ ) containing $1 \mathrm{mg} / \mathrm{L} 4.6$ Diamidino-2Phenylindol (DAPI). The debris was filtered through a $40 \mu \mathrm{m}$ sieve prior to measurement. The flow cytometric measurement was performed with a MoFlo High Speed Cell Sorter (Beckman Coulter, Krefeld, Germany). The nuclei were sorted on the basis of their forward and side scatter profiles as well as on their DAPI signals. The scatter measurements were performed using excitation from an argon ion laser at $488 \mathrm{~nm}$ at $200 \mathrm{~mW}$ power, while the DAPI signal came from excitation with an argon ion laser set up for multiline UV emission (351-356 nm) at $80 \mathrm{~mW}$. DAPI emission was measured from 440 to $460 \mathrm{~nm}$. As a reference to control for the relative intensities of the samples, $20 \mu \mathrm{L}$ of DAPI Reference Standard Beads (Bangs Laboratories, Inc., Cat. 906, Lot-No. 7238) were added to each sample. The DAPI beads could be separated from the nuclei on the basis of their forward versus side scatter profiles. Profiles were separated into DAPI, 1n (1c) and 2n (2c) peaks. The 2n peak represents cells arrested at the G2/M transition [53]. Values presented in Table 2 are the averaged median of the $1 \mathrm{n}$ peak divided by the median of the peak for the DAPI beads, i.e., haploid nuclear DNA content normalized to DAPI control beads. The ratio between the $1 \mathrm{n}$ and $2 \mathrm{n}$ peak was $1.99+/-0.19$ in all samples, supporting correct peak definition (Additional file 5: Table S3). P. patens from Gransden served as an additional control for each experiment $[n=6]$; other accessions were measured up to four times if in doubt of measurement quality.

Table 2 Genome sizes of Funariaceae

\begin{tabular}{|c|c|c|}
\hline Species (revised) & Genome size [1c] & $\begin{array}{l}\text { Physcomitrella } \\
\text { subspecies } \\
\text { (sensu Tan) }\end{array}$ \\
\hline Physcomitrella patens ${ }^{\circ}$ & $0.96 \pm 0.15$ & patens, californica \\
\hline Physcomitrella readeri & $0.96 \pm 0.05$ & readeri, californica \\
\hline Physcomitrella magdalenae & 0.92 & magdalenae \\
\hline Physcomitrium sphaericum & $0.78 \pm 0.43$ & \\
\hline Physcomitrium eurystomum & $1.27 \pm 0.32^{*}$ & \\
\hline Physcomitrium collenchymatum & $1.51 \pm 0.44$ & \\
\hline Physcomitrium pyriforme & $1.33 \pm 0.42^{*}$ & \\
\hline Funaria hygrometrica & $0.44 \pm 0.03^{*}$ & \\
\hline Aphanorrhegma serratum & 0.9 & \\
\hline
\end{tabular}

Genome size shown is the haploid (1c) peak normalized by DAPI beads (see Methods); values are shown +/- standard deviation where applicable. Asterisks show significantly different genome size with regard to $P$. patens (one-sided $t$-test, $\mathrm{p}<0.05$ ). ${ }^{\circ}$ genome size for Gransden $=1.02+/-0.14$, Villersexel "K3" $=0.87$, Del Valle Lake (californica sensu Tan) $=0.75$; for further details see Additional file 5: Table S3. For Physcomitrella, the revised taxon name according to the new classification proposed here is listed on the left, while the former name of the subspecies is listed on the right. 


\section{Sequencing of BRK1 transcripts from six selected Funariaceae}

Total RNA was extracted using the Qiagen RNeasy Plant Mini Kit (Qiagen, Hilden, Germany) according to the manufacturer's instructions, followed by on-column DNAse digestion. The resulting RNA samples from $P$. patens from Gransden (Europe), three accessions from P. eurystomum (Neukirch, Neustadt and Schleiz, Germany) and two accessions from $P$. collenchymatum (Shaw Nature Reserve, Franklin County, MO, USA) were reverse transcribed using Superscript III (Invitrogen ${ }^{\mathrm{rm}}$, Karlsruhe, Germany). The reverse primer BRK1_rev (CACCGTTAGCTTCTC GTTCA) was used for priming the first strand synthesis. The resulting CDNA was then further amplified using both BRK1 primers, BRK1_for (GACAATCGCCATTTTTC GAG) and BRK1_rev, and subsequently Sanger sequenced (GATC Biotech AG, Konstanz, Germany). The primers used were selected based on multiple sequence alignment of clonal sequences.

\section{Quantitative Real-Time PCR and high-resolution-melting} Total RNA was extracted and cDNA was synthesized as described above. cDNA synthesis was verified by PCR. Primers for quantitative Real-Time PCR (qPCR) were designed to specifically amplify a 129 bp long fragment of the exon containing polymorphisms in P. collenchymatum (BRK1_for: GACAATCGCCATTTTTCGAG and BRK1_rev CACCGTTAGCTTCTCGTTCA). Each qPCR was carried out using the SensiMix HRM kit (Bioline, Lickenwalde, Germany) on a LightCycler480 (Roche, Mannheim, Germany) with the following parameters: $95{ }^{\circ} \mathrm{C}$ for $10 \mathrm{~min}$, followed by 50 cycles of $95{ }^{\circ} \mathrm{C}, 60{ }^{\circ} \mathrm{C}$ and $72{ }^{\circ} \mathrm{C}$, for $15 \mathrm{~s}$ each. High resolution melting analysis was subsequently carried out from $65{ }^{\circ} \mathrm{C}$ to $95{ }^{\circ} \mathrm{C}$ with a ramp rate of $0.02{ }^{\circ} \mathrm{C} / \mathrm{s}$. Melting curve data were analyzed using the Gene Scanning software (Roche, Mannheim, Germany) and a sensitivity setting of 0.4 with autogrouping. Pre-melt and post-melt temperatures were chosen in the range of $77^{\circ} \mathrm{C}$ and $84^{\circ} \mathrm{C}$ respectively.

\section{Results}

Paralogs of the single copy gene BRK1 and enlarged genome sizes provide evidence for allopolyploid hybrid Physcomitrium species

In order to gain evidence for homeologs of the single copy gene $B R K 1$ we amplified this gene from selected Funariaceae, including the genera Aphanorrhegma, Physcomitrella, Physcomitrium and Funaria (Table 1, Additional file 2: Table S1). The sequence length amplified from genomic DNA (including the single intron) was approximately 600 nucleotides, but varies between the analyzed species (Table 3 ). In the PCR products, sequence polymorphisms were detected within all accessions of the species $P$. pyriforme, $P$. collenchymatum and P. eurystomum,
Table 3 Sequence polymorphisms of BRK1

\begin{tabular}{lll}
\hline Species (revised) & $\begin{array}{l}\text { BRK1 sequence } \\
\text { length (nucleotides) }\end{array}$ & $\begin{array}{l}\text { Polymorphisms } \\
\text { (exon/intron); gaps }\end{array}$ \\
\hline Physcomitrella patens & 581 & 0 \\
Physcomitrella readeri & 580 & 0 \\
$\begin{array}{l}\text { Physcomitrella magdalenae } \\
\text { Physcomitrium eurystomum }\end{array}$ & 577 & 0 \\
$\begin{array}{l}\text { Physcomitrium } \\
\text { collenchymatum }\end{array}$ & 614 & $27(1 / 26) ; 1$ \\
$\begin{array}{l}\text { Physcomitrium pyriforme } \\
\text { Funaria flavicans }\end{array}$ & 615 & $26(2 / 24) ; 1$ \\
Funaria hygrometrica & 580 & $19(0 / 19) ; 5$ \\
Funaria americana & 546 & 0 \\
Aphanorrhegma serratum & 580 & 0 \\
Ovew & 548 & 0
\end{tabular}

Overview of sequence polymorphisms in the direct PCR product of BRK1 from different Funariaceae. For each species multiple accessions are included. The number of sequence polymorphisms and gaps between two homeologs from the Physcomitrium accessions is shown on the right. For details see Additional file 3: Figure S1.

indicating multiple BRK1 loci within these species. However, no sequence polymorphisms were detected in the Aphanorrhegma, Funaria and Physcomitrella accessions (Table 3). After cloning the respective PCR products, two distinct sequences were clearly distinguishable per Physcomitrium species, respectively (Figure 1A). These loci were compared to the polymorphic direct sequencing product in order to compare the sequence polymorphisms with both clonal sequences of BRK1 (Figure 1B). Most differences between the homeologs occurred in the single intron, while in the case of $P$. collenchymatum and $P$. eurystomum polymorphisms also occurred in the exons (Additional file 3: Figure S1, Table 3). Phylogenetic analyses revealed two distinct clades of the homeologous BRK1 for P. pyriforme, P. eurystomum and P. collenchymatum (Figure 2). Since three of these clades (one per Physcomitrium lineage) cluster with the P. patens (ssp. magdalenae) accession from Africa (labelled P. magdalenae in Figure 2), and two of the other three with P. patens from Europe, they provide evidence for allopolyploidization rather than autopolyploidization.

Flow cytometric measurements were performed for all Funariaceae for which the BRK1 sequence was available, including multiple accessions of Physcomitrella, P. pyriforme, $P$. eurystomum and $P$. collenchymatum (Additional file 2: Table S1). All accessions of Physcomitrella show a comparable genome size as $P$. patens from Gransden (Europe), whereas $P$. pyriforme, $P$. eurystomum and $P$. collenchymatum have a larger size (Table 2), albeit $P$. collenchymatum not significantly ( $\mathrm{p}>0.05$, one-sided $t$ test). These higher amounts of DNA, together with the $B R K 1$ homeologs, indicate that $P$. pyriforme, $P$. collenchymatum and $P$. eurystomum are recent allopolyploids. 


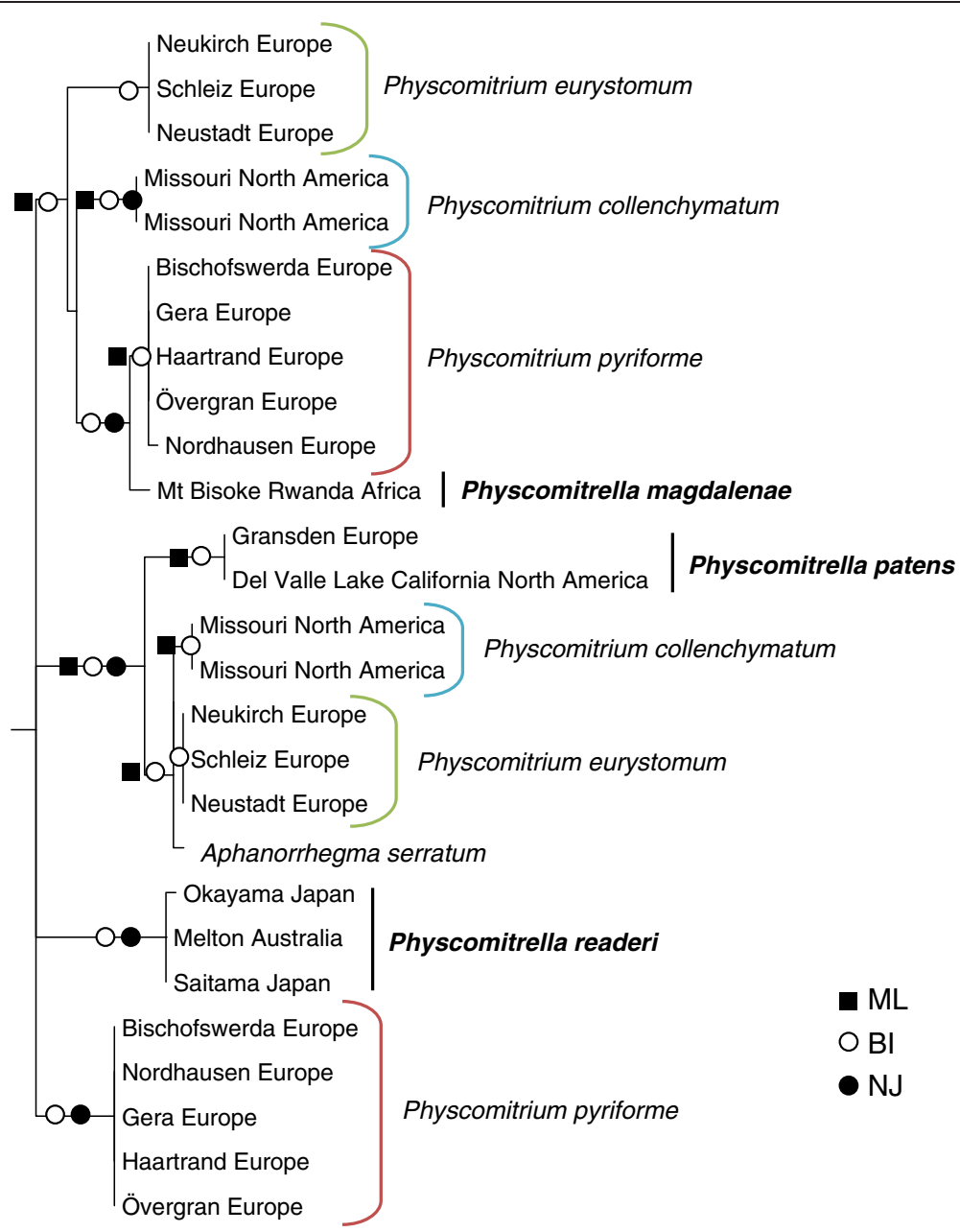

Figure 2 Phylogenetic tree of BRK1. Phylogenetic tree of the nuclear gene BRK1 (Pp1s35_157V6.1) from selected Funariaceae. Three Funaria species (F. hygrometrica, F. flavicans, and F. americana) were used as the outgroup (not shown, see Additional file 6: Figure S3, for details). The cluster representing the Physcomitrium-Physcomitrella species complex shown here is supported by all methods. Due to differing or unresolved branching order, depending on inference method used, the backbone is shown as multifurcating. The three distinct clades of Physcomitrella representing P. readeri (Japan, Australia), P. magdalenae (Africa) and P. patens (Europe and North America) are shown in bold. The distinct paralogous loci of BRK1 for each hybrid species are highlighted with colored brackets. Red brackets represent distinct loci of five $P$. pyriforme accessions from Europe. Blue brackets show multiple loci of two capsules of a P. collenchymatum accession from North America. Green brackets mark distinct loci of BRK1 within three accessions of $P$. eurystomum from Europe. The symbols at the nodes represent support values $>95$ for Maximum Likelihood (ML), Bayesian Inference (BI) and Neighbor Joining (NJ), respectively. They are derived from 1,000 NJ bootstrap samples, respectively show posterior probabilities of Bayesian inference or maximum likelihood quartet puzzling support.

\section{Expression patterns of BRK1 homeologs in Physcomitrium species}

In order to determine whether both loci of BRK1 are expressed in $P$. collenchymatum and $P$. eurystomum, RT-PCR and quantitative Real-Time PCR (qPCR) were performed using primers that cover polymorphisms in the exon (Additional file 3: Figure S1). The existence of both homeologs at the transcript level was confirmed via RT-PCR and subsequent sequencing of the transcripts (Figure 3). The expression pattern of the homeologs was determined with $\mathrm{qPCR}$ and the resulting amplicons were analyzed by high resolution melting (HRM) to distinguish the transcripts. P. patens from Gransden (Europe) was used as a reference. Both $P$. collenchymatum accessions show two distinct expressed transcripts of BRK1, whereas all three P. eurystomum and Physcomitrella yielded only one product in this analysis (Figure 4). Due to the almost identical melting patterns, the auto-grouping of the gene scanning software was not able to distinguish between the $P$. eurystomum accessions (Neukirch and Schleiz, Germany) with their single polymorphism at the exon level, while the two polymorphisms in the exon of $P$. collenchymatum (Table 3) could be resolved. In summary, the exon polymorphisms of $B R K 1$ were confirmed at the transcript level by sequencing (Figure 3 ) and partly by HRM, demonstrating that both homeologs are expressed (Figure 4). 
A)
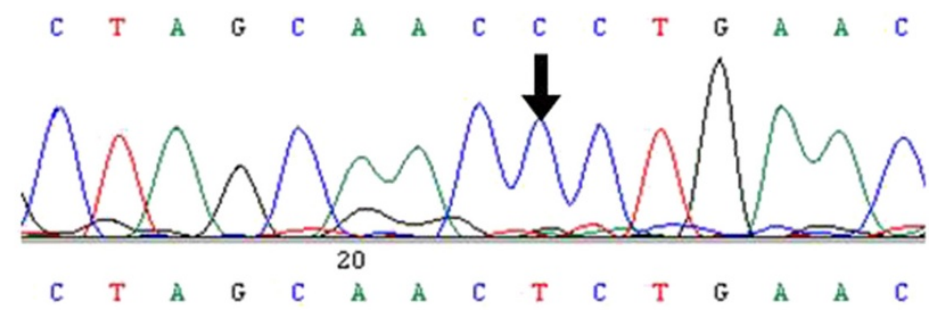

B)

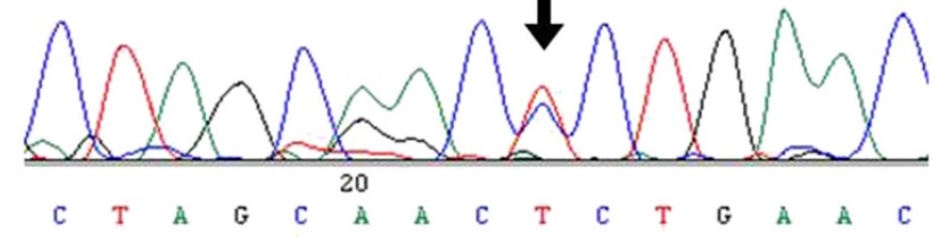

C)

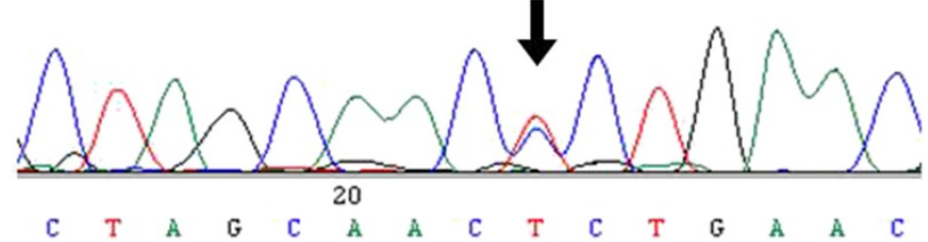

D)

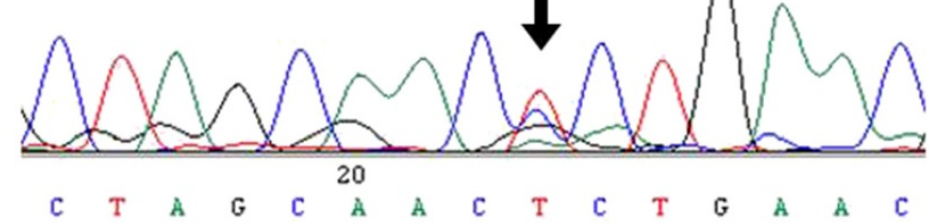

E)

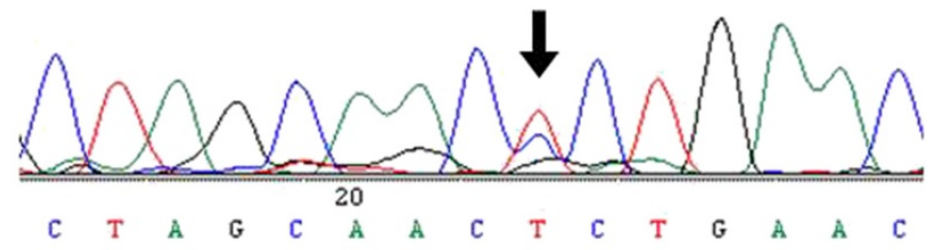

F)

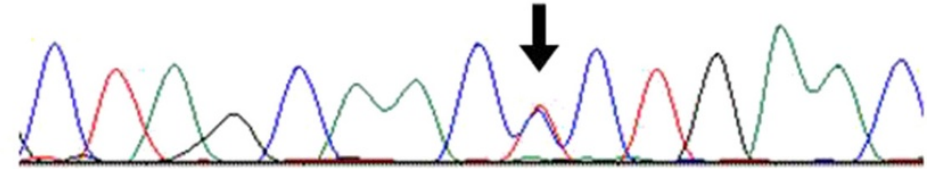

Figure 3 Electropherograms of a polymorphic region within the BRK1 transcript from six selected Funariaceae. Sequencing of an amplified region within the BRK1 transcript from (A) P. patens (Gransden, Europe), P. eurystomum (Schleiz (B), Neukirch (D) and Neustadt (F), Europe) and P. collenchymatum (Shaw Nature Reserve, Franklin County, MO, USA, K1 (C) and K2A (E), USA). Black arrows indicate sequence polymorphisms.

BRK1 as a phylogenetic marker confirms polyphyletic origin of three Physcomitrella species

Based on the high conservation of BRK1 (Additional file 1: Figure S2) and on the fact that the encoding gene $B R K 1$ harbors an intron, we expected the nucleic acid sequence to represent a suitable phylogenetic marker to resolve relationships within the Funariaceae. Different methods of tree inference based on the nucleic acid sequences (exon/intron) all led to essentially the same topology, separating the Funaria sequences from four well supported clades (Additional file 6: Figure S3).
The three clades representing Physcomitrella from Europe and North America (ssp. patens and ssp. californica), Physcomitrella from Australia and Japan (ssp. readeri and ssp. californica) and $P$. patens ssp. magdalenae from Africa are distinct in the BRK1-based phylogeny (Figure 2, Additional file 6: Figure S3). This confirms a polyphyletic origin of these three lineages as previously proposed $[11,12]$ and supports that accessions of P. patens ssp. californica (Del Valle Lake, California and two accessions from Japan) actually belong to two different clades. Moreover, $A$. serratum clusters in a clade together with 


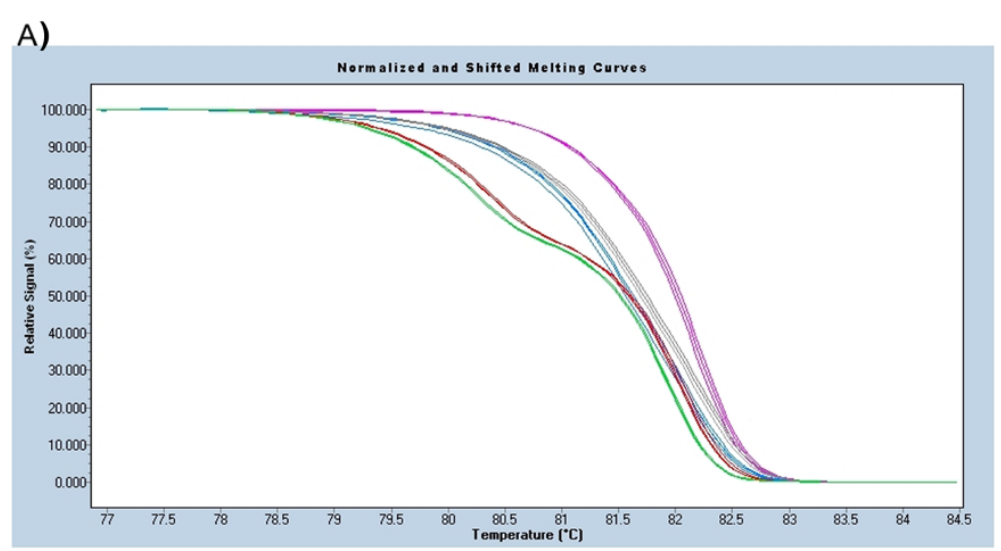

B)

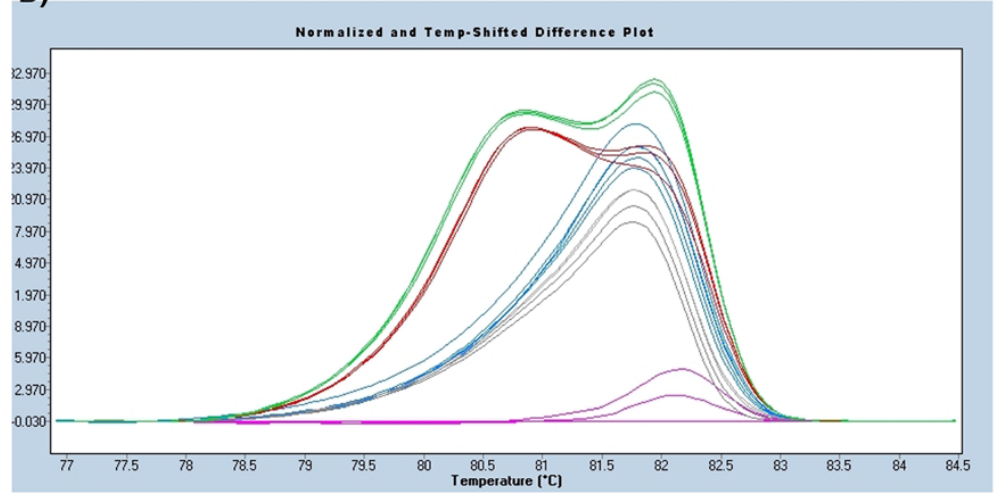

Figure 4 High resolution melting analysis of $B R K 1$. (A) Normalized and temperature shifted high resolution melting curve and (B) difference plot of BRK1 from P. patens (mauve), the two P. collenchymatum accessions K1 (green) and K2A (red) and the three P. eurystomum accessions Neustadt (gray) and Neukirch/Schleiz (both blue); see Additional file 3: Figure S1 for alignment with marked polymorphisms.

P. patens ssp. patens and may therefore be considered to belong to the Physcomitrium-Physcomitrella complex as well.

\section{Genic microsatellites support high genetic distances within the genus Physcomitrella}

Sixty-four EST-derived simple sequence repeat (SSR) loci [48] were analyzed, and all Physcomitrella accessions (Additional file 2: Table S1) turned out to be of different genotypes as measured by SSRs. In total, 238 alleles were detected (average 3.7 alleles per SSR). The phylogenetic tree based on genetic distances (Figure 5) displays a separation of four major clades. One clearly ramified clade consists of European and North American accessions ( $P$. patens ssp. patens and $P$. patens ssp. californica) with small genetic distances, a second clade is formed by the Japanese and the Australian accessions ( $P$. patens ssp. readeri and $P$. patens ssp. californica), while the African P. patens ssp. magdalenae is on a separate branch (Figure 5). The genetic distances of the four Physcomitrella subspecies clusters to one another are as large as, or even larger than, the distance of $P$. sphaericum to each of them. Large banding size shifts and null alleles obtained in the African and the Japanese-Australian clade point towards sequence changes surpassing the enclosed SSRs and affecting the flanking regions. Visualization of the allele presence/absence data as a network (Figure 6) suggests either sexual recombination and thus long range genetic flow, or the parallel (convergent) evolution of alleles. There are only minor differences between the topologies of Figures 5 and 6. In summary, although some of the nodes are not well supported, the genetic distance data support three independently evolved (polyphyletic) Physcomitrella lineages in the same way as the BRK1 data does.

The pattern of editing sites supports independent speciation of Physcomitrella and hybridization of Physcomitrium

Requirement for RNA editing at eight positions in the mitochondrial genome known to be edited in P. patens from Gransden (Europe) was checked for a broad set of accessions across the Physcomitrium-Physcomitrella species complex (Additional file 2: Table S1, Additional file 7: Table S4). Editing sites in nad5, cox1 and $c c m F C$, which were conserved between $F$. hygrometrica and P. patens, as 


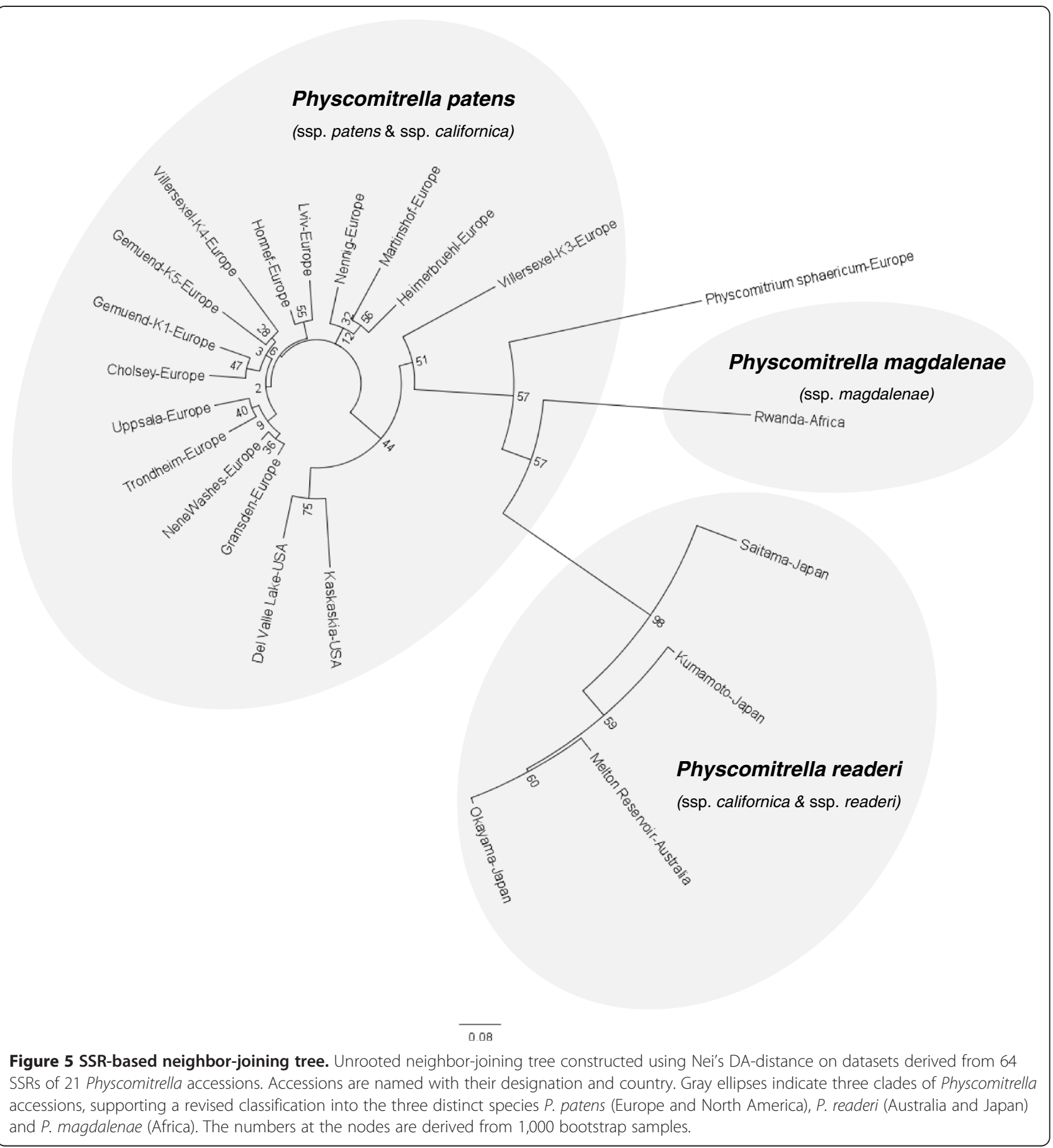

well as rps14eU137SL (for nomenclature see Figure 7), absent from $F$. hygrometrica [34], were found to be conserved in all investigated species. In contrast, the requirement of editing at positions nad3-230 and nad4-272 varied. While all isolates of Physcomitrella from Europe and North America (ssp. patens and ssp. californica) showed editing at both positions, in accessions of Physcomitrella from Australia and Japan (ssp. readeri and ssp. californica) and $P$. patens ssp. magdalenae from
Africa a $\mathrm{T}$ was already encoded at the appropriate positions, making editing obsolete. This supports the independent speciation of at least two Physcomitrella lineages, and the assignment of accessions of $P$. patens ssp. californica into different Physcomitrella lineages.

Clustering of $A$. serratum to the $P$. patens clade, as shown in the BRK1-based phylogeny, was confirmed by the same editing requirements of $A$. serratum and $P$. patens ssp. patens in contrast to Funaria (Figure 7). 


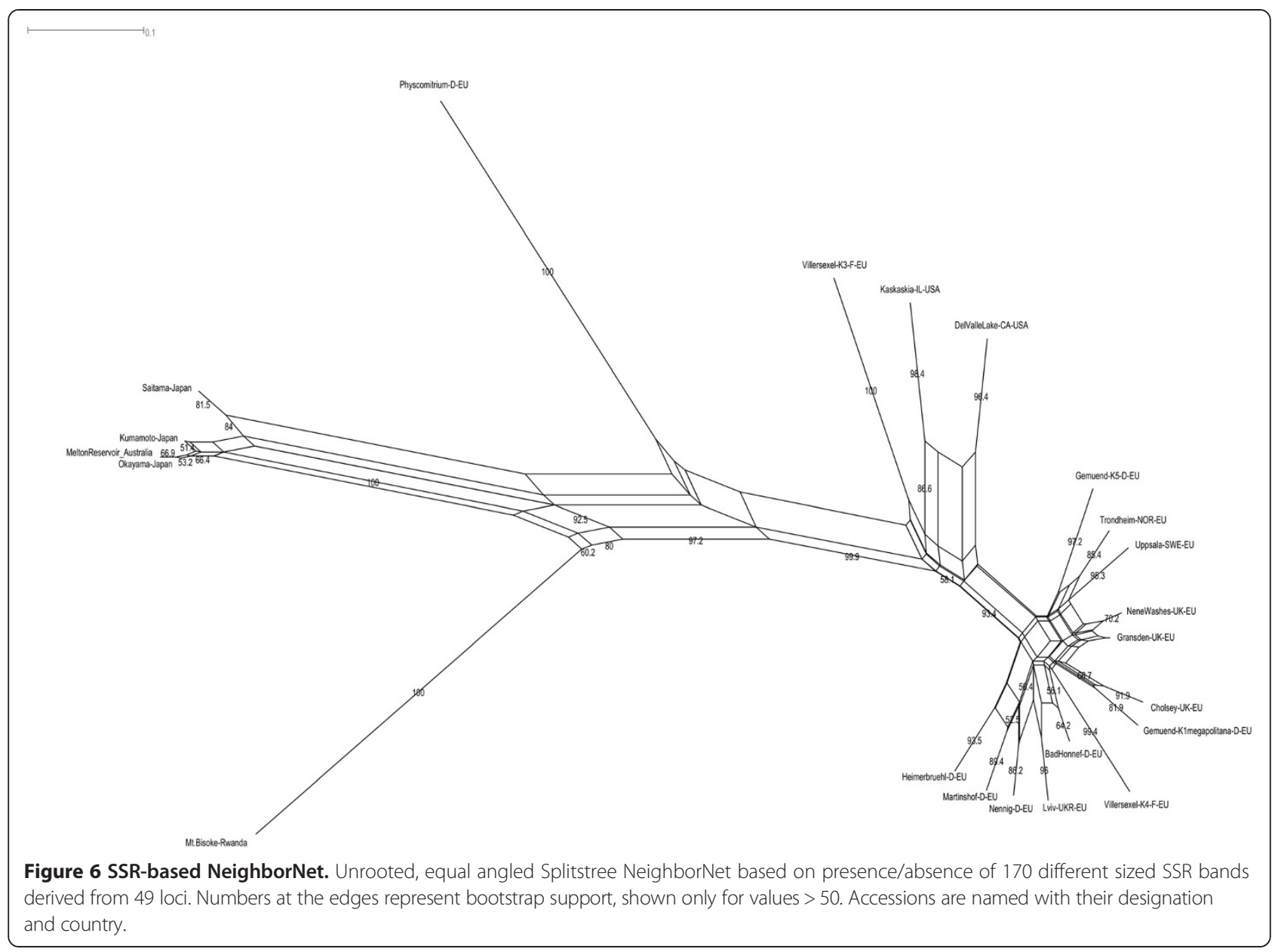

All $P$. pyriforme isolates showed a $\mathrm{T}$ at position nad3eU230SL and a $C$ at position nad4eU272SL at the DNA level (Figure 7), congruent with $P$. pyriforme being a hybrid species derived from divergent parental lines. The $P$. collenchymatum and $P$. eurystomum, as well as the Physcomitrium sphaericum editing sites nad3eU230SL and nad4eU272SL, are akin to the $P$. patens ssp. patens clade (Figure 7). The scenario of $P$. patens ssp. magdalenae developing from the same parental line as P. pyriforme and P. eurystomum is further supported by a site to be edited, ccmFCeU52RC, exclusively identified in accessions of these three lineages. An additional putative editing site in $n a d 5$, nad5eU446SL, is only shared by $P$. pyriforme and $P$. patens ssp. magdalenae.

\section{In vitro comparison of gametophytic morphological features}

Since sporophytic features are not suitable for distinguishing Physcomitrella species, we compared gametophytes grown under identical in vitro conditions. The Californian accession (Additional file 8: Figure S4D, Additional file 9: Figure S5D, Additional file 10: Figure S6B) deviates from the European accessions (Additional file 8: Figure S4A-C,
Additional file 9: Figure S5A-C, Additional file 10: Figure $\mathrm{S6A}$ ) by developing much smaller gametophores with smaller leaflets (i.e., non-vascular leaves or phyllids; cf. Plant Ontology term PO:0025075). However, consistent with the European accessions, the leaflets of the Californian accession develop a costa in most cases, albeit less pronounced and extending to only three quarters of the leaflets (Additional file 10: Figure S6A, S6B). In the Japanese and the Australian accessions the gametophores and leaflets (Additional file 8: Figures S4E, Additional file 9: Figure S5G-I) are much smaller, typically less than half the size as compared to P. patens from Gransden (Europe, Additional file 8: Figure S4A, Additional file 9: Figure S5A, Additional file 10: Figure $\mathrm{S} 6 \mathrm{~A})$, comparable to the Californian accession (Additional file 10: Figure S6B, S6C). However, the leaflets do not develop a costa except in very rare cases where a costa may be present, reaching at most half the length of the leaflets (Additional file 10: Figure S6C). The leaflets of the African accession (Additional file 8: Figure S4F, Additional file 9: Figure S5F) are the largest among all analyzed accessions, with up to twice the surface of the European accessions (Additional file 10: Figure S6D). They are 


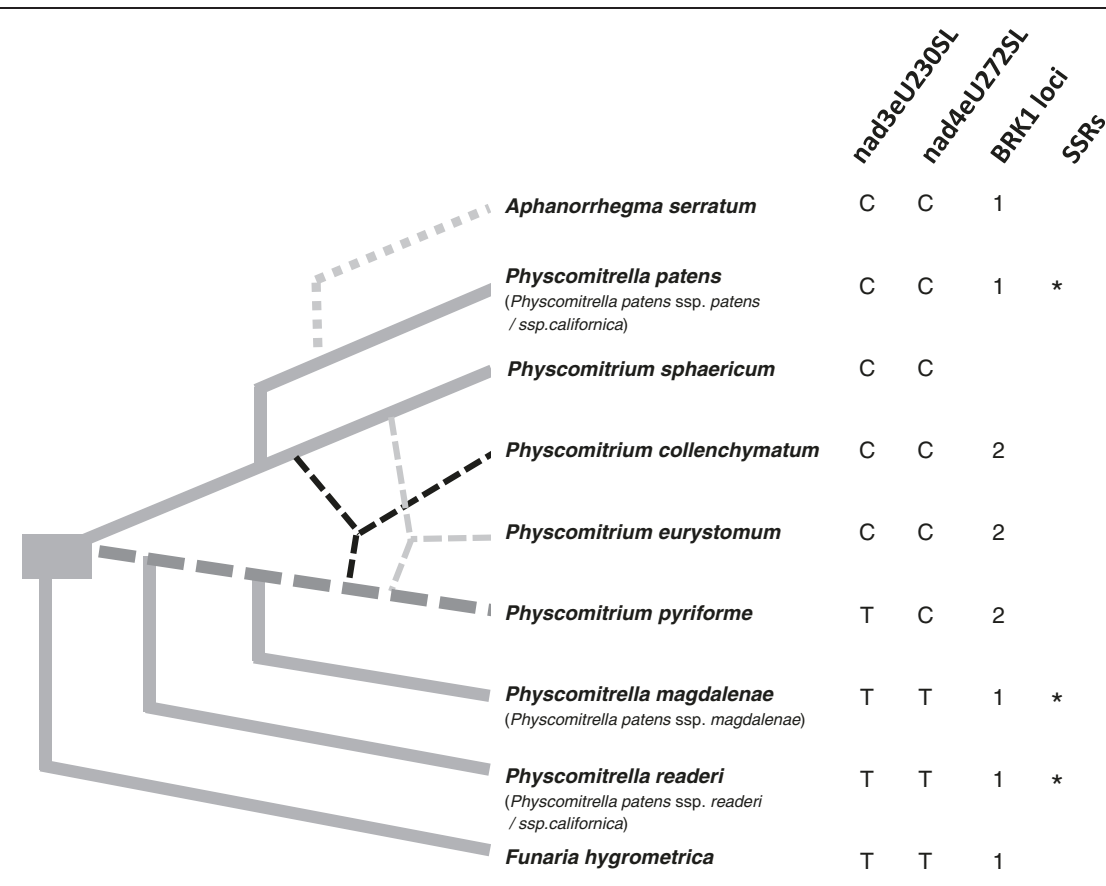

Figure 7 Overview of molecular features supporting the proposed speciation within the Physcomitrium-Physcomitrella species complex. The re-classified species (subspecies following the former classification of Tan 1979 in brackets) are arranged as supported by data presented in this study, modified after [12]. Dashed lines indicate hybridization events resulting in the three species of Physcomitrium. The dotted line illustrates the clustering of $A$. serratum together with $P$. patens. The requirement of editing at particular positions in nad3 and nad4 is shown. The RNA editing site nomenclature consists of affected gene, position in the reading frame and the resulting amino acid codon change induced by RNA editing [32]. C (Cytidine) at the DNA level indicates an editing site, whereas no editing is required in the case of a thymidine (T) at the appropriate position. The number of BRK1 loci (homeologs) is depicted for all analyzed species, while *indicates SSR-based support for the three Physcomitrella species.

orbiculate and much broader than the lanceloate leaflets of the other accessions (Additional file 10: Figures S6D). In summary, leaflet shape and the presence of a costa might be useful to distinguish the Physcomitrella accessions, while leaflet/gametophore size seemed rather variable. Of course, this comparison was done only for single accessions from in vitro cultivated Funariaceae and one can therefore expect more morphological variance in the field as well as from other accessions grown under in vitro conditions.

\section{Discussion}

\section{Hybridization and polyploidization among the} Funariaceae

Here we present data showing that convergent evolution and allopolyploidization are associated with the generation of new species in the Funariaceae. Interspecific hybridization among mosses is an underestimated evolutionary phenomenon [26]. Both, artificial crossings $[24,25,27,54]$ and naturally occurring hybrids have previously been described for the Funariaceae [28-31].

Previously, [12] reported that Physcomitrium collenchymatum and $P$. eurystomum are hybrid species, putatively produced from hybridizations between ancestors of modern P. sphaericum and P. pyriforme. This was based on the observation that these species contained specific polymorphisms (i.e., sphaericum and pyriformelike alleles) at four nuclear loci ( $a d k, a p r, h o 1$ and papr). However, each haploid individual generally contained either the sphaericum or pyriforme-like allele, but never both. This finding was consistent with either homoploid hybrid speciation, or allopolyploid speciation, followed by a loss of one homeolog at each of these loci (fractionation). The one exception to this pattern was the hol locus where four European isolates of $P$. pyriforme contained two divergent copies of this locus.

Here we found that $P$. eurystomum, $P$. collenchymatum, and five European isolates of $P$. pyriforme have genome sizes larger than those of their putative parent lineages, while they also contain two divergent paralogs of BRK1. For these data to be explained by a homoploid hybrid speciation event, we would have to assume both a massive expansion of transposable elements [55] and parallel duplications of the BRK1 locus. Alternatively, these data might reflect an allopolyploidization event followed by the loss of one paralog at the adk, apr, (ho1) and papr loci, a process called fractionation. Our current data do not allow to unambiguously rule out homoploid 
hybrid speciation, but the frequency of homeolog loss following polyploidy in a wide range of organisms [56] suggests that fractionation may be a more plausible explanation. A comparative analysis of the genome-wide patterns of paralog-loss or retention could potentially provide insights into the genetic interactions among loci or dosage sensitivity.

The evolutionary success of hybrids is also known for seed plants, where allopolyploid offspring are sometimes more successful than the parental lines [21,22]. Contrary to seed plants, which contain alleles in the dominant sporophytic generation, mosses contain only a single gene locus in the dominant haploid generation. Therefore, the homeologs generated through an auto- or allopolyploidization event might represent an additional evolutionary advantage since they represent redundant gene copies (akin to alleles), encoded on haploid segregated chromosomes. In allopolyploid hybrids, gains of genes only encoded by one of the two parental genomes might even be more beneficial if they relay an important advantage that one of the parents did not encode.

In the allopolyploid seed plant cotton the majority of expression biases are thought to be due to sub- and neofunctionalization subsequent to the polyploidization event [57]. Indeed, $60 \%$ of the homeologs are found to be transcriptionally biased, e.g., due to cis-regulatory element divergence of the parental genomes [58,59]. Under the conditions applied here, both BRK1 homeologs are expressed in the same tissue in $P$. collenchymatum and $P$. eurystomum, and in the case of $P$. collenchymatum their expression levels seem not to be heavily biased. Allopolyploid cotton has been estimated to be 1.5 MY old [60], while the separation of the parental lineages within the Physcomitrium-Physcomitrella species complex occurred 11 MYA [12]. The hybrids studied here are likely younger than that - but we might also see different patterns or speeds of homeolog divergence between mosses and seed plants in future studies.

With regard to editing site evolution, we consider a $\mathrm{T}$ at nad3_230 and nad4_272 to be the ancestral state, since three lineages (Funaria hygrometrica, Physcomitrella readeri and Physcomitrella magdalenae) share this characteristic, while the gain of a $C$ in these positions can be explained by a single mutation per editing site in the lineage giving rise to Physcomitrium sphaericum and Physcomitrella patens (Figure 7). Under this scenario, editing of nad3eU230SL and nad4eU272SL in the hybrid species $P$. eurystomum, $P$. collenchymatum and $P$. pyriforme might have become feasible by gain (from the parental $P$. sphaericum lineage) of the corresponding nuclear encoded editing factor PPR_56 (Pp1s208_104V6.1, [61]). The gain of the editing requirement (i.e., a $\mathrm{C}$ instead of a $\mathrm{T}$ in the mitochondrial DNA) at one or both positions in the hybrid species can be explained by either maternal transmission of the organelle and thus transfer of the mutation from the P. sphaericum parental lineage, or by the independent gain of mutations (after loss of selection pressure by gain of the nuclear editing factor).

Based on synonymous substitution plots of gene duplication events, a whole-genome duplication in P. patens has been hypothesized and dated to 45 MYA [23]. As this is much later than the Funariidae divergence $\sim 172$ MYA [62], and gene family trees including F. hygrometrica and $P$. patens usually show clear ortholog pairs $[34,63]$, it is reasonable to assume that the previously shown paleopolyploidization [23] is a common ancestral trait of all Funariaceae. In this light, it is surprising that the F. hygrometrica haploid genome size measured here is significantly lower than that of $P$. patens. An explanation for this finding could be a much lower transposon or repetitive element content in F. hygrometrica, or a significantly different $\mathrm{A} / \mathrm{T}$ content. In any case, fractionation (i.e., homeolog loss) apparently occurred to a large extent, since the paleopolyploidization event was not detectable by means of homeologs of $B R K 1$ in those Funariaceae that are not hybrids.

In summary, (sympatric) speciation following allopolyploidization has apparently occurred several times within the Physcomitrium-Physcomitrella species complex.

\section{Revised classification of Physcomitrella}

By comparing the genetic diversity in the analyzed Physcomitrella accessions we found consistency in three main distinctive groupings. One clade includes all European and the two North American accessions (as well as Aphanorrhegma), a second clade encompasses the Japanese and the Australian accessions and the third lineage is represented by the African accession. Hence, our results confirm recently published molecular data concerning the Physcomitrium-Physcomitrella species complex, where an independent origin of three Physcomitrella lineages was assumed [11,12]. Since the genetic distances between the three Physcomitrella clades are as large as, or even larger than, the genetic distances to Physcomitrium species, the three Physcomitrella lineages should be regarded as different species. Based on the results presented here, we propose a revised classification, which divides Physcomitrella into three species:

\section{Physcomitrella patens (Hedw.) Bruch et Schimp.,} Bryol. Eur. 1: 13, 1849.

Basionym: Phascum patens Hedw. Spec. Musc. 20, 1801. Synonyms: Physcomitrium patens (Hedw.) Mitt., Ann. Mag. Nat. Hist., ser. 2, 8: 363, 1851.

Physcomitrella patens ssp. californica (H.A.

Crum \& L.E. Anderson) B.C. Tan, J. Hattori Bot. Lab. 46: 334, 1979. 
This taxon encompasses the European and North American accessions of $P$. patens ssp. patens and the North American accessions of $P$. patens ssp. californica.

2. Physcomitrella readeri (Müll. Hal.) I.G. Stone \& G.A.M. Scott, J. Bryol. 7: 604, 1974.

Basionym: Ephemerella readeri Müll. Hal., Hedwigia 41: 120, 1902.

Synonyms: Physcomitrium readeri Müll. Hal., Gen. Musc. Frond. 112. 1900, nom. inval., lacking species description. Physcomitridium readeri (Müll. Hal.) G. Roth, Außereurop. Laubm. 250, 1911. Physcomitrella patens ssp. readeri (Müll.Hal.) B.C.Tan, J. Hattori Bot. Lab. 46: 334, 1979.

This taxon encompasses the Australian accessions of P. patens ssp. readeri and the Japanese accessions of P. patens ssp. californica.

3. Physcomitrella magdalenae De Sloover, Bull. Jard. Nat. Belg. 45 : 131, 1975.

Synonyms: Physcomitrella patens ssp. magdalenae (De Sloover) B.C. Tan, J. Hattori

Bot. Lab. 46: 334, 1979. Aphanorrhegma magdalenae (De Sloover) Ochyra, Acta Bot. Hung. 29: 178, 1983.

This taxon encompasses the African accessions of $P$. patens ssp. magdalenae.

Following this classification, $P$. patens, disjunct in North America and Europe, can be clearly distinguished from $P$. readeri and $P$. magdalenae by distinct gametophytic (but not sporophytic) morphological as well as molecular characteristics.

According to the $B R K 1$ phylogeny and the pattern of editing sites, the stegocarpous $A$. serratum may also be classified as Physcomitrella, although Physcomitrella is cleistocarpous. Thus, the Funariaceae type species, $F$. hygrometrica, represents the most highly complex end of a morphological series, with Physcomitrella/Aphanorrhegma representing the other end. The origin of a cleistocarpous taxon from a stegocarpous taxon is found several times within the acrocarpous mosses. Species with cleistocarpous and stegocarpous members are found e.g. in the genus Pottia, where P. bryoides and P. recta are cleistocarpous while the remaining species are stegocarpous, having either no peristome, or a rudimentary or even well-developed peristome. In conclusion, as previously supposed, sporophytic characteristics cannot be used to resolve the phylogeny of the Funariaceae [11].

Considering an independent evolution for Physcomitrella from Physcomitrium ancestors [12] and the observed (phylo) genetic distances, the analyzed accessions of the Physcomitrium-Physcomitrella species complex may in consequence be classified as a single genus. In this case,
Physcomitrium would be the correct genus name as it is older than Physcomitrella, dating back to 1829. Given our present taxon sampling and data set, Physcomitrella, Physcomitrium and Aphanorrhegma form a species complex that may or may not include additional genera, such as Entosthodon and Bryobeckettia [11]. Therefore, further phylogenetic studies including more accessions and more genera are required in order to confidently propose a revision in taxonomic classification at the genus level (i.e., uniting the species of the Physcomitrium-Physcomitrella species complex into a monophyletic genus Physcomitrium).

\section{Disjunct occurrence and long range dispersal of Physcomitrella}

The habitats of the Physcomitrella accessions used in this work show clear similarities, as they grow on moist, often disturbed ground, typically in close proximity to water. Physcomitrella shows a cosmopolitan, probably originally holarctic distribution (excluding boreal and tropical regions). While one might expect genetic distances to correlate with geographic distances, the two $P$. patens isolates from Gemünd (Germany) cluster with one of the French Villersexel accessions, "K4" (Gemünd "K5"), and the English Cholsey accession (Gemünd "K1") respectively; the latter Gemünd accession was characterized as var. megapolitana in the field. Also, the accessions from Villersexel (France) cluster in different parts of the $P$. patens genetic distance tree. These genetic distances provide evidence for either high intra-population diversity or long range dispersal.

Moss spores are able to survive in mud for prolonged periods of time, a trait considered important for ephemeral species [64]. In particular, Physcomitrella is known to quickly appear on the muddy banks of reservoirs after draining. $P$. patens spores are larger and fewer in number (30 $\mu \mathrm{m}$ diameter, 8,000-16,000 per capsule) than those of F. hygrometrica (23 $\mu \mathrm{m}, 60,000-170,000)$ [65], making them a bigger energy reservoir that might be able to boost growth as soon as the conditions are suitable. Spores smaller than $20 \mu \mathrm{m}$ are easily dispersed by wind [64] and long range dispersal via this mode is evident for Funaria hygrometrica [66], also considering its cosmopolitan distribution. Given the larger spore size of P. patens, along with the fact that the plants grow on wet soil and have a cleistocarpous capsule, spore dispersal by wind is possible but appears unlikely. Although long distance spore dispersal by wind cannot be excluded for Physcomitrella, we suggest that spore distribution by birds [67] along migration routes may also contribute to the observed disjunct distribution patterns. The disjunct distribution of $P$. patens on both sides of the Northern Atlantic may be explained by use of the East Atlantic flyway, while the North American continent is covered by a total of four partially overlapping flyways [68], potentially allowing the spores to spread 
across the continent. Concerning $P$. readeri, which is found in Japan and Australia, but also in Europe [69], nearly identical ribosomal spacer data between the accessions from England, Australia and Japan suggests long range dispersal. The disjunct habitats in Japan and Australia are covered by the West Pacific as well as by the East Asian-Australasian flyway used by migratory birds [68]. Since the East Asian-Australasian flyway is geographically overlapping with the East Atlantic flyway, dispersal from Japan/Australia to Europe [69] is theoretically possible, although less likely than, e.g., the exchange between Japan and Australia. We hypothesize that Physcomitrella might be dispersed via migratory (water) birds along flyways since the observed habitats follow a distribution pattern coinciding with such flyways. When the SSR data are visualized as a network, potential genetic flow is also supported. While reticulate structures are present mainly within $P$. patens and $P$. readeri, there is also evidence for alleles that are potentially exchanged between both species. Interestingly, based on the SSR data no exchange is evident between $P$. magdalenae, $P$. sphaericum and any of the other accessions.

\section{Independent secondary reduction of Funariaceae sporophyte complexity}

Considering the fact that characteristic structural features of moss sporophytes can be correlated with specialized habitats [70], the most likely secondary reduction of the Physcomitrella sporophyte to a cleistocarpous capsule with reduced seta and increased spore size may be interpreted as an adaptation to an ephemeral life style. Given the polyphyletic origin of the three cryptic (with regard to sporophytic features) Physcomitrella species, a convergent evolutionary process in which the seta is reduced and the capsule is no longer dehiscent can be assumed. $P$. patens inhabits an ephemeral habitat, e.g. on banks of rivers and ponds which dry up in summer or autumn. The species has a short life cycle of up to two months from spore germination to the development of spores [65]. Besides a reduced sporophyte, a shortened life cycle also represents a typical adaptation to a highly unpredictable and ephemeral habitat [70]. In Physcomitrella, the gametophore is reduced as well, forming a small rosette with its apparent main function being the production of gametangia and spore capsules. As a semi-aquatic moss, the spores are most likely released into water or mud. This mode of spore dispersal does not require a lid or a peristome at the capsule, but rather the disintegration of the capsule when mature spores have developed.

The Funariaceae feature highly variable sporophyte architectures, and sporophytes of interspecies hybrids usually display intermediate or maternal phenotypes [27]. It has been argued that evolutionary pressure may force changes to moss sporophyte architecture rather than conserving it $[11,70]$. In summary, we hypothesize that probably parapatric speciation via establishing an ecological niche, namely the resting of spores in the mud, their potential dispersal by birds rather than by wind, and an ephemeral life cycle, has led to the independent evolution of a reduced sporophyte in the three Physcomitrella lineages - making them cryptic species if one considers sporophyte morphology alone.

\section{Conclusions}

In this study we present molecular insights into the global genetic diversity of the Physcomitrium-Physcomitrella species complex, providing evidence for sympatric speciation involving allopolyploidization, as well as for convergent evolution leading to a reduced sporophyte, large spores, and a colonization of a humid, ephemeral, moist habitat, possibly concomitant with possible parapatric speciation. Primarily, the sequenced P. patens isolate from Gransden (Europe) has to date been widely used as an experimental model in comparative plant sciences, followed by the French isolate Villersexel "K3" that has been used for the generation of a genetic map [71] and for crossing experiments with "Gransden" and other isolates [54]. The present collection of axenic in vitro cultures of Funariaceae accessions, together with the molecular data presented here, is expected to boost the research into natural variation and trait evolution of this emerging model system representing haploid-dominant land plants. Resequencing of Funariaceae accessions will lead to insights into genome evolution and its coupling to trait evolution.

\section{Availability of supporting data}

The data sets supporting the results of this article are included within the article (and its additional files). BRK1 sequence data have been submitted to Genbank and are available under the accession numbers KC337119KC337148.

\section{Additional files}

Additional file 1: Figure S2. Alignment of BRK1 amino acid sequences. Multiple sequence alignment of BRK1 amino acid sequences from several land plants. The conserved blocks used for primer design are denoted by red boxes. The leading five letters of each sequence identifier denote the species in the common abbreviation (first three letters of the genus, followed by the first two letters of the species, e.g. PHYscomitrella PAtens).

Additional file 2: Table S1. Funariaceae collection (detailed) and data matrix.

Additional file 3: Figure S1. Alignment of genomic BRK1 sequences. Multiple sequence alignment of amplified and clonal genomic sequences of BRK1 from different Funariaceae. The exon region is shown in white letters, the intron region in black letters. The species names are sorted alphabetically. Accessions with only one locus of BRK1 are represented by one sequence of directly sequenced PCR product, whereas two 
representative clonal sequences are shown for each accession with two loci of BRK1 (P. collenchamytum, P. eurystomum, and P. pyriforme).

Polymorphisms in the exon regions are depicted in red (P. collenchymatum) and orange (P. eurystomum) boxes.

Additional file 4: Table S2. SSR data.

Additional file 5: Table S3. Flow cytometric analyses (detailed).

Additional file 6: Figure S3. Phylogenetic tree using BRK1.

Neighbor-joining tree of using BRK1 (Pp1s35_157V6.1) from selected

Funariaceae. The three distinct clades of Physcomitrella are highlighted in bold.

The distinct loci of BRK1 for each Physcomitrium species are highlighted in

boxes. Green boxes: distinct loci of $P$. pyriforme accessions from Europe. Blue

boxes: distinct loci of one P. collenchymatum accession from North America

from two different capsules. Red boxes: distinct loci of BRK1 from three

accessions of $P$. eurystomum from Europe. The numbers at the nodes are derived from 1,000 bootstrap samples.

Additional file 7: Table S4. Editing site conservation along the Physcomitrium-Physcomitrella species complex.

Additional file 8: Figure S4. Habitus of gametophytes. Physcomitrella gametophytes grown under standardized in vitro conditions on solid mineral medium. (A) Physcomitrella patens, [Physcomitrella patens ssp. patens] from Gransden, Europe; (B) Physcomitrella patens [patens ssp. patens] from Lviv, Europe; (C) Physcomitrella patens [patens ssp. patens] from Illinois, USA; (D) Physcomitrella patens [patens ssp. california] from California, USA; (E) Physcomitrella readeri [patens ssp. readeri] from Australia; (F) Physcomitrella magdalenae [patens ssp. magdalenae] from Rwanda, Africa; (G) Physcomitrella readeri [patens ssp. californica] from Okayama, Japan; (H) Physcomitrella readeri [patens ssp. californica] from Kumamoto, Japan; (I) Physcomitrella readeri [patens ssp. californica] from Saitama, Japan.

Additional file 9: Figure S5. Habitus of gametophores and leaflets. Physcomitrella accessions grown under standardized in vitro conditions on solid mineral medium. (A) Physcomitrella patens [Physcomitrella patens ssp. patens] from Gransden, Europe; (B) Physcomitrella patens [patens ssp. patens] from Lviv, Europe; (C) Physcomitrella patens [patens ssp. patens] from Illinois, USA; (D) Physcomitrella patens [patens ssp. california] from California, USA; (E) Physcomitrella readeri [patens ssp. readeri] Australia; (F) Physcomitrella magdalenae [patens ssp. magdalenae] from Rwanda, Africa; (G) Physcomitrella readeri [patens ssp. california] Okayama, Japan; (H) Physcomitrella readeri [patens ssp. californica] from Kumamoto, Japan; (I) Physcomitrella readeri [patens ssp. california] from Saitama, Japan.

Additional file 10: Figure S6. Leaflet details. Leaflets of (A) Physcomitrella patens [Physcomitrella patens ssp. patens] from Gransden, Europe; (B) Physcomitrella patens [patens ssp. californica] from Del Valle Lake, California, USA; (C) Physcomitrella readeri [patens ssp. californica] from Japan, Okayama; (D) Physcomitrella magdalenae [patens ssp. magdalenae] from Rwanda, Africa. Both accessions from Europe and North America reveal a costa, in contrast to those from Okayama, Japan. Physcomitrella from Rwanda, Africa has orbiculate leaflets in comparison to the lanceolate leaflets of the other accessions.

\section{Competing interests}

The authors declare that they have no competing interests.

\section{Authors' contributions}

SAR conceived of most of the study. MvS, RR and SAR conceived of the SSR and phenotypic part of the study, MvS performed it. AKB and SAR designed most of the experiments. MSR and SAR designed the editing analyses, MvS the SSR analyses. AKB performed the BRK1 experiments, MSR the editing site analyses, STH the qPCRs/melting studies, MF the flow cytometry/melting studies, SAR the statistics. AKB and SAR performed the phylogenetic analyses. $A K B, S M D, B C T$ and SAR hypothesized on species evolution. AKB and SAR drafted the manuscript, with participation of all authors. All authors read and approved the final manuscript.

\section{Acknowledgements}

This work is dedicated to our friend and colleague Jan-Peter Frahm who passed away unexpectedly in February 2014. He contributed much to this project by collecting plant material, providing taxonomical background and discussing species evolution among mosses.

We are grateful to all contributors (Table 1/Additional file 2: Table S1) for their help on collecting and determining Funariaceae and to T. Tiko for technical assistance. We would like to thank B. Goffinet for helpful comments on this work.

This work was supported by the University of Freiburg, the Ministry of Science, Research and Art of the Federal State of Baden-Württemberg (RiSC grant to SAR) and by the German Federal Ministry of Education and Research (Freiburg Initiative for Systems Biology, 0313921 to SAR).

\section{Author details}

${ }^{1}$ Faculty of Biology, University of Freiburg, Schänzlestr. 1, 79104 Freiburg, Germany. ${ }^{2}$ Plant Biotechnology, Faculty of Biology, University of Freiburg, Schänzlestr. 1, 79104 Freiburg, Germany. ${ }^{3}$ FRISYS Freiburg Initiative for Systems Biology, University of Freiburg, 79104 Freiburg, Germany. ${ }^{4}$ Present address: Käthe-Kollwitz-Schule, Reserveallee 5, 76646 Bruchsal, Germany. ${ }^{5}$ Nees Institute for Biodiversity of Plants, University of Bonn, Meckenheimer Allee 170, 53115 Bonn, Germany. ${ }^{6}$ Department of Medicine I, University Medical Center Freiburg, 79106 Freiburg, Germany. ${ }^{7}$ University of Florida, Gainesville, FL 32611, USA. ${ }^{8}$ FRIAS Freiburg Institute for Advanced Studies, University of Freiburg, 79104 Freiburg, Germany. ${ }^{9}$ BIOSS Centre for Biologica Signalling Studies, University of Freiburg, 79104 Freiburg, Germany. ${ }^{10}$ Plant Cell Biology, Faculty of Biology, University of Marburg, Karl-von-Frisch-Str. 8, 35043 Marburg, Germany. ${ }^{11}$ The University and Jepson Herbaria, University of California, Berkeley, CA 94720, USA.

Received: 19 December 2013 Accepted: 4 July 2014

Published: 11 July 2014

\section{References}

1. Rensing SA, Lang D, Zimmer AD, Terry A, Salamov A, Shapiro H, Nishiyama T, Perroud PF, Lindquist EA, Kamisugi Y, Tanahashi T, Sakakibara K, Fujita T, Oishi K, Shin-I T, Kuroki Y, Toyoda A, Suzuki Y, Hashimoto S, Yamaguchi K, Sugano S, Kohara Y, Fujiyama A, Anterola A, Aoki S, Ashton N, Barbazuk WB, Barker E, Bennetzen JL, Blankenship R, et al: The Physcomitrella genome reveals evolutionary insights into the conquest of land by plants. Science 2008, 319(5859):64-69.

2. Zimmer AD, Lang D, Buchta K, Rombauts S, Nishiyama T, Hasebe M, Van de Peer $Y$, Rensing SA, Reski R: Reannotation and extended community resources for the genome of the non-seed plant Physcomitrella patens provide insights into the evolution of plant gene structures and functions. BMC Genomics 2013, 14:498.

3. Sugiura C, Kobayashi Y, Aoki S, Sugita C, Sugita M: Complete chloroplast DNA sequence of the moss Physcomitrella patens: evidence for the loss and relocation of rpoA from the chloroplast to the nucleus. Nucleic Acids Res 2003, 31(18):5324-5331.

4. Terasawa K, Odahara M, Kabeya Y, Kikugawa T, Sekine Y, Fujiwara M, Sato N: The mitochondrial genome of the moss Physcomitrella patens sheds new light on mitochondrial evolution in land plants. Mol Biol Evol 2007, 24(3):699-709.

5. Tan BC: A new classification for the genus Physcomitrella B.S.G. J Hattori Bot Lab 1979, 46:327-336.

6. Wijk R: Index Muscorum. Utrecht, NL: Regnum Vegetabile; 1959:1959-1969.

7. Tan BC: Physcomitrella patens (Musci: Funariaceae) in North America. The Bryologist 1978, 81(4):561-567.

8. Ochi H: A revision of the family Funariaceae (Musci) in Japan and the adjacent regions. Jap J Bot 1968, 20:1-34.

9. Mueller F: Neue und bemerkenswerte Moosfunde aus Zaire. Trop Bryology 1995, 10:81-90.

10. Sloover JL: Note de bryologie africaine III. - Physcomitrella magdalenae sp. nov. Bulletin du Jardin botanique national de Belgique/Bulletin van de National Plantentuin van België 1975, 45(1/2):131-135.

11. Liu Y, Budke JM, Goffinet B: Phylogenetic inference rejects sporophyte based classification of the Funariaceae (Bryophyta): rapid radiation suggests rampant homoplasy in sporophyte evolution. Mol Phylogenet Evol 2012, 62(1):130-145.

12. McDaniel SF, von Stackelberg M, Richardt S, Quatrano RS, Reski R, Rensing SA: The speciation history of the Physcomitrium-Physcomitrella species complex. Evolution 2010, 64(1):217-231. 
13. Perroud PF, Quatrano RS: BRICK1 is required for apical cell growth in filaments of the moss Physcomitrella patens but not for gametophore morphology. Plant Cell 2008, 20(2):411-422.

14. Engel PP: The induction of biochemical and morphological mutants in the moss Physcomitrella patens. Am J Bot 1968, 55(4):438-446.

15. Reski R, Faust M, Wang XH, Wehe M, Abel WO: Genome analysis of the moss Physcomitrella patens (Hedw.) B.S.G. Mol Gen Genet 1994, 244(4):352-359.

16. Beike AK, Rensing SA: The Physcomitrella patens genome - a first stepping stone towards understanding bryophyte and land plant evolution. Trop Bryology 2010, 31:43-49.

17. Frahm J-P: Biologie der Moose. Heidelberg, Berlin: Spektrum Akademischer Verlag; 2001

18. Fritsch R: Index To Bryophyte Chromosome Counts, vol. 40. Berlin, Stuttgart: J. Cramer/Gebrueder Borntraeger; 1991.

19. Crow KD, Wagner GP: Proceedings of the SMBE Tri-National Young Investigators' Workshop 2005. What is the role of genome duplication in the evolution of complexity and diversity? Mol Biol Evol 2006, 23(5):887-892.

20. Ohno S: Evolution by gene duplication. New York: Springer; 1970

21. Soltis PS, Soltis DE: The role of hybridization in plant speciation. Annu Rev Plant Biol 2009, 60:561-588.

22. Van de Peer $Y$, Maere $S$, Meyer A: The evolutionary significance of ancient genome duplications. Nat Rev Genet 2009, 10(10):725-732

23. Rensing SA, Ick J, Fawcett JA, Lang D, Zimmer A, Van de Peer Y, Reski R: An ancient genome duplication contributed to the abundance of metabolic genes in the moss Physcomitrella patens. BMC Evol Biol 2007, 7(1):130.

24. Wettstein F: Gattungskreuzungen bei Moosen. Z Indukt AbstammungsVererbungs/ 1924, 33:253-257.

25. Wettstein F: Genetik. In Manual of Bryology. Edited by Verdoorn F. Hague: The Netherlands: (ed. F. Verdoorn). Martinus Niehoff; 1932:233-272.

26. Natcheva $\mathrm{R}$, Cronberg N: What do we know about hybridization among bryophytes in nature? Can J Bot 2004, 82:1687-1704.

27. Rensing SA, Beike AK, Lang D, Greilhuber J, Wendel JF, Leitch IJ, Doležel J: Evolutionary importance of generative polyploidy for genome evolution of haploid-dominant land plants. In Plant Genome Diversity. vol. in press. Vienna, New York: Springer; 2012.

28. Andrews AL: A new hybrid in Physcomitrium. Torreya 1918, 18:52-54.

29. Andrews AL: Taxonomic notes. II. Another natural hybrid in the Funariaceae. The Bryologist 1942, 45(6):176-178.

30. Britton EG: Contributions to American Bryology IX. Bulletin of the Torrey Botanical Club 1895, 22(2):62-68.

31. Pettet A: Hybrid sporophytes in Funariaceae. I. Hybrid sporophytes on Physcomitrella patens (Hedw.) B. \& S., and Physcomitrium sphaericum (Schkuhr) Brid. in Britain. Trans Br Bryol Soc 1964, 4:642-648.

32. Rüdinger M, Funk HT, Rensing SA, Maier UG, Knoop V: RNA editing: only eleven sites are present in the Physcomitrella patens mitochondrial transcriptome and a universal nomenclature proposal. Mol Genet Genomics 2009, 24:24.

33. Miyata Y, Sugiura C, Kobayashi Y, Hagiwara M, Sugita M: Chloroplast ribosomal S14 protein transcript is edited to create a translation initiation codon in the moss Physcomitrella patens. Biochim Biophys Acta 2002, 1576(3):346-349.

34. Rüdinger M, Szovenyi P, Rensing SA, Knoop V: Assigning DYW-type PPR proteins to RNA editing sites in the funariid mosses Physcomitrella patens and Funaria hygrometrica. Plant J 2011, 67(2):370-380.

35. Beike AK, Horst NA, Rensing SA: Axenic bryophyte in vitro cultivation. Endocyt Cell Res 2010, 20:102-108.

36. Steeves TA, Sussex IM CRP: In vitro studies in abnormal growth of prothalli of the brachen fern. Am J Bot 1955, 42:232-245.

37. Reski R, Abel WO: Induction of budding on chloronemata and caulonemata of the moss, Physcomitrella patens, using isopentenyladenine. Planta 1985, 165(3):354-358

38. Doyle JJ, Doyle JL: Isolation of plant DNA from fresh tissue. Focus 1990 $12: 13-15$

39. Edgar RC: MUSCLE: a multiple sequence alignment method with reduced time and space complexity. BMC Bioinformatics 2004, 5:113.

40. Clamp M, Cuff J, Searle SM, Barton GJ: The Jalview Java alignment editor. Bioinformatics 2004, 20(3):426-427.

41. Frickenhaus S, Beszteri B: Quicktree-SD; 2008

42. Howe K, Bateman A, Durbin R: QuickTree: building huge NeighbourJoining trees of protein sequences. Bioinformatics 2002, 18(11):1546-1547.
43. Ronquist F, Huelsenbeck JP: MrBayes 3: Bayesian phylogenetic inference under mixed models. Bioinformatics 2003, 19(12):1572-1574.

44. Schmidt HA, Strimmer K, Vingron M, von Haeseler A: TREE-PUZZLE: maximum likelihood phylogenetic analysis using quartets and parallel computing. Bioinformatics 2002, 18(3):502-504.

45. Edwards $\mathrm{K}$, Johnstone $\mathrm{C}$, Thompson C: A simple and rapid method for the preparation of plant genomic DNA for PCR analysis. Nucleic Acids Res 1991, 19(6):1349.

46. Tamura K, Peterson D, Peterson N, Stecher G, Nei M, Kumar S: MEGA5: molecular evolutionary genetics analysis using maximum likelihood, evolutionary distance, and maximum parsimony methods. Mol Biol Evol 2011, 28(10):2731-2739.

47. Lenz H, Knoop V: PREPACT 2.0: Predicting C-to-U and U-to-C RNA Editing in Organelle Genome Sequences with Multiple References and Curated RNA Editing Annotation. Bioinform Biol Insights 2013, 7:1-19.

48. von Stackelberg M, Rensing SA, Reski R: Identification of genic moss SSR markers and a comparative analysis of twenty-four algal and plant gene indices reveal species-specific rather than group-specific characteristics of microsatellites. BMC Plant Biol 2006, 6:9.

49. Nei M, Tajima F, Tateno Y: Accuracy of estimated phylogenetic trees from molecular data. II. Gene frequency data. J Mol Evol 1983, 19(2):153-170.

50. Saitou N, Nei M: The neighbor-joining method: a new method for reconstructing phylogenetic trees. Mol Biol Evol 1987, 4(4):406-425.

51. Langella O: Populations 1.2.28. Population Genetic Software (Individuals or Populations Distances, Phylogenetic Trees). available at http://www. bioinformatics.org/downloads/index.php?file_id=538. 2002.

52. Huson DH, Bryant D: Application of phylogenetic networks in evolutionary studies. Mol Biol Evol 2006, 23(2):254-267.

53. Schween G, Gorr G, Hohe A, Reski R: Unique tissue-specific cell cycle in Physcomitrella. Plant Biol 2003, 5(1):50-58.

54. Perroud PF, Cove DJ, Quatrano RS, McDaniel SF: An experimental method to facilitate the identification of hybrid sporophytes in the moss Physcomitrella patens using fluorescent tagged lines. New Phytol 2011, 2(10):1469-8137.

55. Ungerer MC, Strakosh SC, Zhen Y: Genome expansion in three hybrid sunflower species is associated with retrotransposon proliferation. Curr Biol 2006, 16(20):R872-R873.

56. Lynch M, Conery JS: The evolutionary fate and consequences of duplicate genes. Science 2000, 290:1151-1155.

57. Flagel L, Udall J, Nettleton D, Wendel J: Duplicate gene expression in allopolyploid Gossypium reveals two temporally distinct phases of expression evolution. BMC Biol 2008, 6:16.

58. Chaudhary B, Flagel L, Stupar RM, Udall JA, Verma N, Springer NM, Wendel JF: Reciprocal silencing, transcriptional bias and functional divergence of homeologs in polyploid cotton (gossypium). Genetics 2009, 182(2):503-517.

59. Flagel LE, Wendel JF: Evolutionary rate variation, genomic dominance and duplicate gene expression evolution during allotetraploid cotton speciation. New Phytol 2010, 186(1):184-193.

60. Senchina DS, Alvarez I, Cronn RC, Liu B, Rong J, Noyes RD, Paterson AH, Wing RA, Wilkins TA, Wendel JF: Rate variation among nuclear genes and the age of polyploidy in Gossypium. Mol Biol Evol 2003, 20(4):633-643.

61. Ohtani S, Ichinose M, Tasaki E, Aoki Y, Komura Y, Sugita M: Targeted gene disruption identifies three PPR-DYW proteins involved in RNA editing for five editing sites of the moss mitochondrial transcripts. Plant Cell Physiol 2010, 51(11):1942-1949.

62. Newton AE, Wikström N, Bell N, Forrest LL, Ignatov MS: Dating The Diversification Of The Pleurocarpous Mosses. In Pleurocarpous mosses: Systematics and Evolution, vol. Special Volume 71. Edited by Tangney N. Boca Raton: Systematics Association: CRC Press; 2006.

63. Zobell O, Faigl W, Saedler H, Munster T: MIKC* MADS-box proteins: conserved regulators of the gametophytic generation of land plants. $\mathrm{Mol}$ Biol Evol 2010, 27(5):1201-1211.

64. Glime JM: Bryophyte Ecology. In Volume 1 Physiological Ecology. Edited by Glime JM. 2007. vol. 1: Ebook sponsored by Michigan Technological University and the International Association of Bryologists.

65. Nakosteen PC, Hughes KW: Sexual life cycle of three species of Funariaceae in culture. Bryologist 1978, 81:307-314.

66. McDaniel SF, Shaw AJ: Selective sweeps and intercontinental migration in the cosmopolitan moss Ceratodon purpureus (Hedw.) Brid. Mol Ecol 2005, 14:1121-1132 
67. Lewis LR, Behling E, Gousse H, Qian E, Elphick CS, Lamarre JF, Bety J, Liebezeit J, Rozzi R, Goffinet B: First evidence of bryophyte diaspores in the plumage of transequatorial migrant birds. PeerJ 2014, 2:e424.

68. Boere GC, Stroud DA: The Flyway Concept: What It is And What It Isn't. Edinburgh, UK: The Stationery Office; 2006

69. Hooper EJ, Duckett JG, Cuming AC, Kunin WE, Pressel S: Ephemerella readeri Müll. Hal. (Physcomitrella readeri (Müll. Hal.) I.G. Stone \& G.A.M. Scott, Funariidae, Bryophyta): a genus and species new to Europe. J Bryol 2010, 32:256-264

70. Vitt DH: Adaptive Modes of the Moss Sporophyte. The Bryologist 1981, 84(2):166-186.

71. Kamisugi Y, von Stackelberg M, Lang D, Care M, Reski R, Rensing SA, Cuming AC: A sequence-anchored genetic linkage map for the moss, Physcomitrella patens. Plant J 2008, 56(5):855-866.

doi:10.1186/1471-2148-14-158

Cite this article as: Beike et al: Molecular evidence for convergent evolution and allopolyploid speciation within the PhyscomitriumPhyscomitrella species complex. BMC Evolutionary Biology 2014 14:158.

\section{Submit your next manuscript to BioMed Central and take full advantage of:}

- Convenient online submission

- Thorough peer review

- No space constraints or color figure charges

- Immediate publication on acceptance

- Inclusion in PubMed, CAS, Scopus and Google Scholar

- Research which is freely available for redistribution 